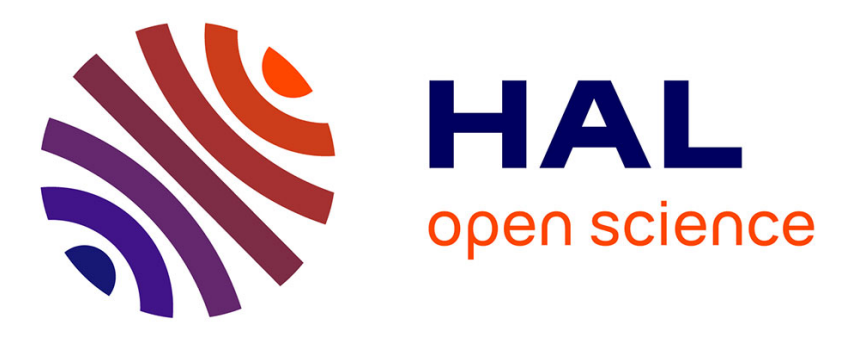

\title{
Ti-Modified LaFeO $3 / \beta$-SiC Alveolar Foams as Immobilized Dual Catalysts with Combined Photo-Fenton and Photocatalytic Activity
}

Patricia García-Muñoz, Fernando Fresno, Christophe Lefèvre, Didier Robert, Nicolas Keller

\section{To cite this version:}

Patricia García-Muñoz, Fernando Fresno, Christophe Lefèvre, Didier Robert, Nicolas Keller. TiModified LaFeO 3 / $\beta$-SiC Alveolar Foams as Immobilized Dual Catalysts with Combined Photo-Fenton and Photocatalytic Activity. ACS Applied Materials \& Interfaces, 2020, 10.1021/acsami.0c16647. hal-03053307

\section{HAL Id: hal-03053307 https://hal.science/hal-03053307}

Submitted on 10 Dec 2020

HAL is a multi-disciplinary open access archive for the deposit and dissemination of scientific research documents, whether they are published or not. The documents may come from teaching and research institutions in France or abroad, or from public or private research centers.
L'archive ouverte pluridisciplinaire HAL, est destinée au dépôt et à la diffusion de documents scientifiques de niveau recherche, publiés ou non, émanant des établissements d'enseignement et de recherche français ou étrangers, des laboratoires publics ou privés. 


\title{
Ti-modified $\mathrm{LaFeO}_{3} / \beta$-SiC alveolar foams as immobilized dual catalyst with combined photo-Fenton and photocatalytic activity
}

\author{
Patricia García-Muñoz, ${ }^{a}, *$ Fernando Fresno, ${ }^{b}$ Christophe Lefevre, ${ }^{c}$ Didier Robert, ${ }^{a}$ \\ Nicolas Keller ${ }^{a, *}$
}

${ }^{a}$ Institut de Chimie et Procédés pour l'Energie, l'Environnement et la Santé (ICPEES), CNRS/University of Strasbourg, 25 rue Becquerel, Strasbourg, France

${ }^{\text {b }}$ Photoactivated Processes Unit, IMDEA Energy, Móstoles, 28935, Madrid, Spain

${ }^{\mathrm{c}}$ Institut de Physique et de Chimie des Matériaux de Strasbourg (IPCMS), CNRS/University de Strasbourg, 23 rue du Loess, Strasbourg, France corresponding author*patricia.gmunoz@upm.es ;*nkeller@unistra.fr

KEYWORDS : alveolar $\beta$-SiC foam ; dual Ti-modified $\mathrm{LaFeO}_{3}$ catalyst ; photoassisted CWPO ; photocatalysis ; water treatment ; photonic efficiencies

\section{ABSTRACT.}

Ti-modified $\mathrm{LaFeO}_{3} / \beta$-SiC alveolar foams were used as immobilized, highly robust dual catalyst with combined photo-Catalytic Wet Peroxide Oxidation (CWPO) and photocatalytic activity under UV-A light. They were prepared by incipient wetness impregnation of a $\beta$-SiC foam support, by implementing a sol-gel Pechini synthesis at the foam surface in the presence of dried amorphous sol-gel titania as titanium source. Physico-chemical and catalytic features suggest the stabilization at the foam surface of a 
substituted $\mathrm{La}_{1-\mathrm{x}} \mathrm{Ti}_{\mathrm{x}} \mathrm{FeO}_{3}$ catalyst analogous to its powdery counterpart. Taking 4chlorophenol removal in water as a model reaction, its dual nature enables both high reaction rates and full TOC conversion, due to a synergy effect, while its macroscopic structure overcomes the drawback of working with powdery catalysts. Further, it yields photonic efficiencies for degradation and mineralization of ca. $9.4 \%$ and $38 \%$, respectively, that strongly outperform those obtained with a reference $\mathrm{TiO}_{2} \mathrm{P} 25 / \beta-\mathrm{SiC}$ foam photocatalyst. The enhancement of the catalyst robustness upon Ti modification prevents any Fe leaching to the solution, and therefore the optimized macroscopic foam catalyst with $10 \mathrm{wt} . \%$ catalyst loading operates through pure heterogeneous surface reactions, without any activity loss during reusability test cycles. 


\section{INTRODUCTION}

The emergence of biorecalcitrant hazardous organic pollutants that are refractory to the conventional biological water treatments based on activated sludge or even membrane bioreactors, combined with increasingly stringent environmental govern regulations, has created strong incentive for the development of new sustainable and efficient water treatment technologies ${ }^{1}$.

The lack of efficient processes for water treatment is the driving force for the development of Advanced Oxidation Processes (AOPs), based on the generation at room temperature of highly oxidative $\mathrm{HOx}^{\circ}$ radicals that react non-selectively with the refractory organic pollutants provoking their depletion ${ }^{2}$. Special attention has been given to the $\mathrm{H}_{2} \mathrm{O}_{2}$-mediated Fe-based Fenton process, or its heterogenized counterpart known as catalytic wet peroxide oxidation (CWPO), and to semiconductor photocatalysis, since they both operate with a high efficiency and relatively low investment/running costs. While Fenton-like processes benefit from high degradation rates, they suffer from incomplete mineralization of the refractory targets that result from the well-known complexation of Fe by refractory carboxylic compounds. By contrast, heterogeneous photocatalysis can reach total mineralization of a large range of refractory organic compounds, but with far lower reaction rates. Combining both AOPs, heterogenized photo-CWPO and photocatalysis, within a single-phase catalyst is consequently a promising strategy investigated only recently for intensifying the mineralization process by a synergy effect ${ }^{3,4}$.

Only a few works have reported on the use of Fe-containing single-phase catalysts for the light- and $\mathrm{H}_{2} \mathrm{O}_{2}$-mediated catalytic degradation of organic pollutants in water, using notably natural iron oxide $\left(\alpha-\mathrm{Fe}_{2} \mathrm{O}_{3}\right)^{5}$, natural $\mathrm{FeTiO}_{3}$ ilmenite ${ }^{3,4}$, spinel $\mathrm{ZnFe}_{2} \mathrm{O}_{4}$ 
${ }^{6}$ and $\mathrm{Ba}$-doped $\mathrm{BiFeO}_{3}{ }^{7}$. However, the catalysts suffer from incomplete TOC conversion or from too low reaction rates. Recently, we have demonstrated that the synergy effect between photocatalysis and photo-CWPO operates very efficiently on a narrow band gap $\mathrm{La}_{1-\mathrm{x}} \mathrm{Ti}_{\mathrm{x}} \mathrm{FeO}_{3}$ orthoferrite powdery catalyst with $11 \% \mathrm{Ti} \rightarrow$ La substitution degree and a 4 at.\% Ti content. This catalyst gives rise to full mineralization of 4-chlorophenol (4-CP) in water at high reaction rates under UV-A or visible light ${ }^{8-10}$. This dual catalyst was prepared as a powder by modifying a Pechini sol-gel synthesis using a dried amorphous titania as titanium source, while the cationic substitution extent was controlled by both the amount and the nature of the titanium source introduced, as well as by the final calcination temperature. The key feature was driven by the partial cationic substitution within the orthoferrite network, that strongly enhanced the reaction rates and increased the catalyst robustness by more than two orders of magnitude compared to its unsubstituted counterpart, with a complete inhibition of Fe release and the absence of any loss of catalytic activity along several test cycles.

However, water treatment using powdery nanoparticulate catalysts requires the frequent implementation of time-consuming and costly filtration recovery steps, that drastically reduce the process viability. In the search for more efficient water treatment processes operating in a continuous mode, open-cell alveolar solid foams have attracted significant interest as structured supports for immobilizing photocatalysts, due to their ability of acting as active static mixer while working at an ultra-low pressure drop, and maintaining a better light transmission to the reactor core than packed-bed supports ${ }^{11-15}$.

Self-bonded (binder-free) $\beta$-SiC foams prepared via the Shape Memory Synthesis replica method stand out in comparison to polymer, metallic and other ceramic foams such as eg. cordierite, alumina or zirconia ${ }^{14,16}$, thanks to good characteristics like high thermal/chemical stability which allows them to withstand severe conditions, and high 
density of oxygenated surface groups, thereby favouring the anchorage of catalysts ${ }^{17,18}$. While $\beta$-SiC foams have received strong interest for immobilizing titania photocatalysts 17-23, to date only scarce works have reported on their use - and more globally on the use of alveolar foams - as support for Fenton-like catalysts. For example, magnetite powder onto $\mathrm{Ni}$ and $\mathrm{FeCrAl}^{24}, \mathrm{BiFeO}_{3} / \mathrm{Ni}^{25}$, sludge carbon/ $/ \mathrm{SiC}^{26}$, ferrisilicate/ $\mathrm{SiC}^{27}$ or $\mathrm{Fe}-\mathrm{ZSM}$ 5/SiC ${ }^{28}$ have been reported as dark-Fenton foam catalysts for CWPO. However, these foam-based catalysts usually suffer from a low stability of the Fe-containing supported active phase, and from uncomplete mineralization of the effluent. It is worth noting that photo-Fenton-like degradation was recently achieved on perovskite-type catalysts supported on cordierite honeycomb monoliths, ${ }^{29}$ and on $\mathrm{TiO}_{2}-\mathrm{FeSO}_{4}$ immobilized on metallic foams ${ }^{30}$.

Here, we report a reusable and robust immobilized catalyst for water treatment based on Ti-modified $\mathrm{LaFeO}_{3}$ supported on an alveolar $\beta$-SiC foam, prepared by synthesizing the Ti-doped ferrite in situ at the foam surface. The removal of the 4-CP has been chosen as test reaction under UV-A light, as a representative of industrial wastewater refractory pollutants in AOP studies ${ }^{31}$. We demonstrate that this macroscopic Ti-substituted $\mathrm{LaFeO}_{3} / \beta$-SiC foam dual catalyst combines the advantages of both photocatalysis and photo-CWPO AOPs. This catalyst leads to high mineralization rates and complete TOC conversions at circumneutral $\mathrm{pH}$ conditions, without any Fe release to the solution, and overcomes the drawbacks of working with powdery catalysts.

\section{EXPERIMENTAL}

\subsection{Materials}

4-CP $(>99 \%)$ and $\mathrm{H}_{2} \mathrm{O}_{2}(>30 \%)$ were purchased from Sigma Aldrich. $\mathrm{Fe}\left(\mathrm{NO}_{3}\right)_{3}$ 
nonahydrate, $\mathrm{La}\left(\mathrm{NO}_{3}\right)_{3}$ hexahydrate, citric acid hydrate $\left(\mathrm{C}_{6} \mathrm{H}_{8} \mathrm{O}_{7} \cdot \mathrm{xH}_{2} \mathrm{O}, 99.5 \%\right)$ and titanium tetraisopropoxide (TTIP, 97\%) were purchased from Sigma Aldrich.

Commercially available Aeroxide $(\mathrm{C}) \mathrm{TiO}_{2} \mathrm{P} 25$ (hydrophilic fumed titanium oxide, $>99.5 \%$ ) was obtained from Evonik (Germany). Self-bonded $\beta$-SiC alveolar foams with medium specific surface area were synthesized by the SICAT-ACM GmbH Company (Willstätt, Germany) according to the shape memory synthesis (SMS) replica method, in which a pre-shaped polyurethane foam is transformed into the corresponding $\beta$-SiC carbide $^{32}$. The method relies on the fact that the original macrostructural features of a solid, i.e. its macroscopic shape, are retained after synthesis. $\beta$-SiC foams can thus be manufactured with adjustable shapes suitable for adaption to the reactor geometry. In this work, 8 pore per inch (PPI) $\beta$-SiC alveolar foams with a mean cell size of $5400 \pm 700 \mu \mathrm{m}$, a mean window size of $2300 \pm 600 \mu \mathrm{m}$ and a mean bridge diameter of $575 \pm 80 \mu \mathrm{m}$ have been used. They have an open porosity of $0.91 \pm 0.05$, and a geometrical specific surface area, derived from the open porosity and the mean strut diameter according to the model developed by Edouard and co-workers ${ }^{33-36}$, of $626 \pm 200 \mathrm{~m}^{-1}$.

\subsection{In situ synthesis of the $\beta-\mathrm{SiC}$ foam supported $\mathrm{Ti}$-modified $\mathrm{LaFeO}_{3}$ catalysts}

The $\beta$-SiC alveolar foams were used as $5 \mathrm{~cm}(d) \times 2 \mathrm{~cm}(h)$ disks. Prior to the ferrite synthesis onto the foam, the alveolar foams were calcined at $1000{ }^{\circ} \mathrm{C}$ to remove by combustion residual unreacted carbon species that might be released to the aqueous solution during the reaction, as well as to form a natural washcoat made of amorphous oxygenated phases at the surface of the foams, thus favouring the in-situ aqueous phase synthesis of the supported ferrite.

The $\beta$-SiC foam supported Ti-modified $\mathrm{LaFeO}_{3}$ catalysts were prepared by incipient wetness impregnation of the $\beta$-SiC foam support disks, that allows the modified sol-gel 
Pechini synthesis to be performed in-situ at the foam surface. The impregnation suspension was similar to that used for synthesizing the $\mathrm{LaFeO}_{3}$-based catalysts as powder ${ }^{9}$. First, stoichiometric amounts of $\mathrm{La}\left(\mathrm{NO}_{3}\right)_{3} \cdot 6 \mathrm{H}_{2} \mathrm{O}$ and $\mathrm{Fe}\left(\mathrm{NO}_{3}\right)_{3} \cdot 9 \mathrm{H}_{2} \mathrm{O}$ were dissolved in distilled water $(15 \mathrm{~mL})$, together with $\mathrm{C}_{6} \mathrm{H}_{8} \mathrm{O}_{7} \cdot \mathrm{xH}_{2} \mathrm{O}$ used as complexation agent in a stoichiometric molar ratio with respect to the metallic ions. The titanium source, either commercial $\mathrm{TiO}_{2}$ Aeroxide $(\mathrm{P} 25$ or a dried amorphous titania was then dispersed in this solution. The amorphous titania was obtained by a sol-gel synthesis under basic conditions using TTIP as a precursor, as detailed in Supporting Information SI1 and in Garcia-Munoz et al. ${ }^{10}$, with a final drying step at $110^{\circ} \mathrm{C}$ for $12 \mathrm{~h}$. The concentrations of the precursors in the impregnation suspension were adjusted for preparing the $\mathrm{LaFeO}_{3}$ phase with contents of $5 \mathrm{wt} . \%, 10 \mathrm{wt} . \%$ and $20 \mathrm{wt} . \%$ relative to the $\beta$-SiC foam support, and the titanium added corresponded to a nominal amount of $10 \mathrm{wt} . \%$ in terms of $\mathrm{TiO}_{2}$ with respect to the theoretical amount of $\mathrm{LaFeO}_{3}$ phase synthesized (details in Table $\mathrm{S} 1$ ).

The precursor suspension was kept under stirring during the full impregnation process. Due to the low total pore volume of the $\beta$-SiC foam support, the dropwise impregnation of the foam was sequentially implemented, with an intermediate drying step at $80{ }^{\circ} \mathrm{C}$ for $30 \mathrm{~min}$ between two consecutive impregnation steps. The process was repeated several times until the full impregnation of the suspension. The foam was dried overnight at $80{ }^{\circ} \mathrm{C}$ and calcined following a heating cycle as reported by Gosovi et al. ${ }^{37}$ and similar to that used for synthesising $\mathrm{LaFeO}_{3}$ and Ti-modified $\mathrm{LaFeO}_{3}$ powders ${ }^{8,10}$, with a heating rate of $5^{\circ} \mathrm{C} / \mathrm{min}$, holding the temperature at $600{ }^{\circ} \mathrm{C}$ for $2 \mathrm{~h}$, before further maintaining a temperature plateau for $2 \mathrm{~h}$ at $800{ }^{\circ} \mathrm{C}$.

The obtained catalysts were labelled as $\mathrm{P} 25-\mathrm{LFO} / \beta-\mathrm{SiC}$ foam and $\mathrm{SG}-\mathrm{LFO} / \beta-\mathrm{SiC}$ foam, whether the commercial $\mathrm{TiO}_{2}$ Aeroxide $C$ P25 or the dried amorphous titania, respectively, was used as titanium source. A reference titanium-free $\beta$-SiC foam based 
catalyst, labelled as $\mathrm{LFO} / \beta-\mathrm{SiC}$ foam, was synthesized following the same protocol without any addition of titanium source.

The weight load of the $\beta$-SiC foam supported catalyst was calculated relative to the weight of the $\beta$-SiC foam support by weight difference. With a weight of $5 \mathrm{~g} \pm 0.05 \mathrm{~g}$ for the $\beta$-SiC foam disks, contents of $5 \mathrm{wt.} \%, 10 \mathrm{wt.} \%$ and $20 \mathrm{wt.} \%$ of LFO correspond to 25 $\mathrm{mg}, 50 \mathrm{mg}$ and $100 \mathrm{mg}$ of immobilized LFO phase, respectively.

\subsection{Characterisation techniques}

X-ray diffraction (XRD) patterns were recorded at room temperature in a $\theta / \theta$ mode on a Brucker D8 Advance diffractometer equipped with a monochromatic copper radiation source $\left(\mathrm{K}_{\alpha}=1.54056 \AA\right)$, with a scan step of $0.02^{\circ}$. Advanced XRD recording was carried out on a Bruker D8 Discover diffractometer. Details are explained in Supporting Information SI2.

The Brunauer-Emmett-Teller (BET) specific surface area has been calculated from the $\mathrm{N}_{2}$ adsorption isotherm recorded on a Micrometrics Tristar 3000 using $\mathrm{N}_{2}$ as adsorbate at $-196{ }^{\circ} \mathrm{C}$, with a prior outgassing at $250^{\circ} \mathrm{C}$ overnight to desorb the impurities and moisture.

Scanning Electron Microscopy (SEM) has been performed in a secondary mode on a Zeiss GeminiSEM 500 microscope equipped with a FEG Schottky source.

The transmittance of the $\beta$-SiC foam based catalysts was defined as the fraction of the incident light, in terms of UV-A irradiance, being transmitted through the materials. It was measured by varying the foam thickness, using a wideband RPS900-W rapid portable spectroradiometer from International Light Technology. 


\subsection{Typical reaction procedure}

The 4-CP oxidation tests were carried out in a batch beaker-type glass reactor (55 $\mathrm{mm}$ internal diameter) at atmospheric pressure, at room temperature (using a cooling bath) and with $\mathrm{H}_{2} \mathrm{O}_{2}$ as main oxidant. In a typical reaction procedure, the supported photocatalyst was placed in $100 \mathrm{~mL}$ of a $25 \mathrm{mg} / \mathrm{L}$ aqueous solution of 4-CP (initial organic carbon concentration of $14.8 \mathrm{ppm}$ ). Prior to irradiation, the 4-CP solution was stirred for $1 \mathrm{~h}$ in the dark in the presence of the immersed foam photocatalyst to ensure the establishment of the adsorption/desorption equilibrium. After adding hydrogen peroxide at the stoichiometric concentration corresponding to a complete mineralization of the initial pollutant (i.e. $125 \mathrm{mg} / \mathrm{L}$ ), the experiments were carried out under stirring (350 rpm) and UV-A irradiation (Philips 24W/10/4P lamps, $60 \mathrm{~W} / \mathrm{m}^{2} ; \lambda_{\max }=365 \mathrm{~nm}$, ).

At each time interval, $8 \mathrm{~mL}$ of solution was sampled and then filtered through 0.20 $\mu \mathrm{m}$ membrane filters to remove the photocatalyst powder, and then the concentration of 4-CP was determined by UV-visible spectrophotometry by monitoring the disappearance of the main absorption peak at $\lambda=224 \mathrm{~nm}^{38}$. Total Organic Carbon (TOC) measurements were performed using a Shimadzu TOC-L analyzer. The hydrogen peroxide concentration was measured by colorimetric titration using the $\mathrm{TiOSO}_{4}$ method ${ }^{39}$ and the Fe leached during the time-course of the reaction was quantified by the orthophenanthroline method ${ }^{40}$. Photonic efficiencies, as defined by the IUPAC recommendations ${ }^{38}$, were calculated both for $4-\mathrm{CP}$ oxidation and for mineralization, as described in Supporting Information SI3 and Figure S1. 


\section{RESULTS AND DISCUSSION}

\subsection{Characterization}

Optical images of the bare $\beta$-SiC foam and the supported LFO-based catalysts, shown in Fig. 1A-D, evidence the macroscopic homogeneity of the coating on the foam support. The coating homogeneity is favoured by the presence at the $\beta$-SiC surface of a $\mathrm{SiO}_{\mathrm{x}} \mathrm{C}_{\mathrm{y}} / \mathrm{SiO}_{2}$ oxygenated layer with nanometric thickness ${ }^{41,42}$. This amorphous layer improves the hydrophilic character of the support surface. By acting as as a natural washcoat that interacts with the aqueous precursors during the Pechini sol-gel synthesis 43-46, this oxygenated surface layer favours the formation of covalent oxygen-mediated bonds at the $\mathrm{LFO} / \beta-\mathrm{SiC}$ interface during the final calcination/crystallization step at $800^{\circ} \mathrm{C}$. They are responsible for the strong anchorage of the supported phase and prevent from any loss of materials to the solution, similarly to what is observed for ceramic foam supported $\mathrm{TiO}_{2}$ systems ${ }^{15,17}$. It must be said, that we cannot rule out the existence of a thin interfacial phase - that would slightly structurally differs from the supported LFO , and that would facilitate a very firm attachment between two phases with totally different structures to be effective, by acting as a glue or allowing a progressive structural change to take place from the support surface to the supported LFO crystals. 

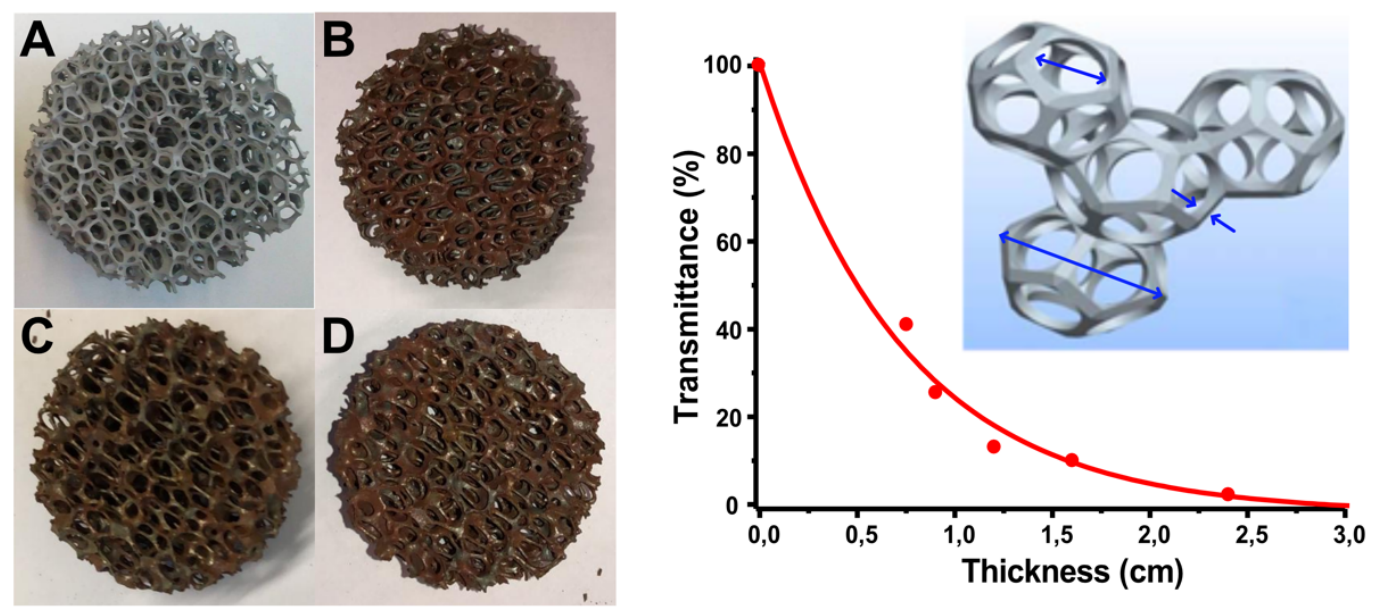

Figure 1: (left) Optical images of (A) the bare $\beta$-SiC foam support, (B) the LFO/ $\beta$-SiC foam catalyst (LFO $10 \mathrm{wt}$ \%), and (C,D) the Ti-modified LFO/ $\beta$-SiC foam catalysts (P25and $\mathrm{SG}-\mathrm{LFO} / \beta-\mathrm{SiC}$, respectively). (right) Transmittance of the alveolar $\beta$-SiC foam recorded at $\lambda=365 \mathrm{~nm}$, with a schematic drawing of the $\beta$-SiC foam model developed by Edouard that consists in the packing of regular pentagonal dodecahedron characterized by the cell size, the strut or bridge diameter, and the window size or pore diameter as the most characteristic parameters ${ }^{33,47}$. 


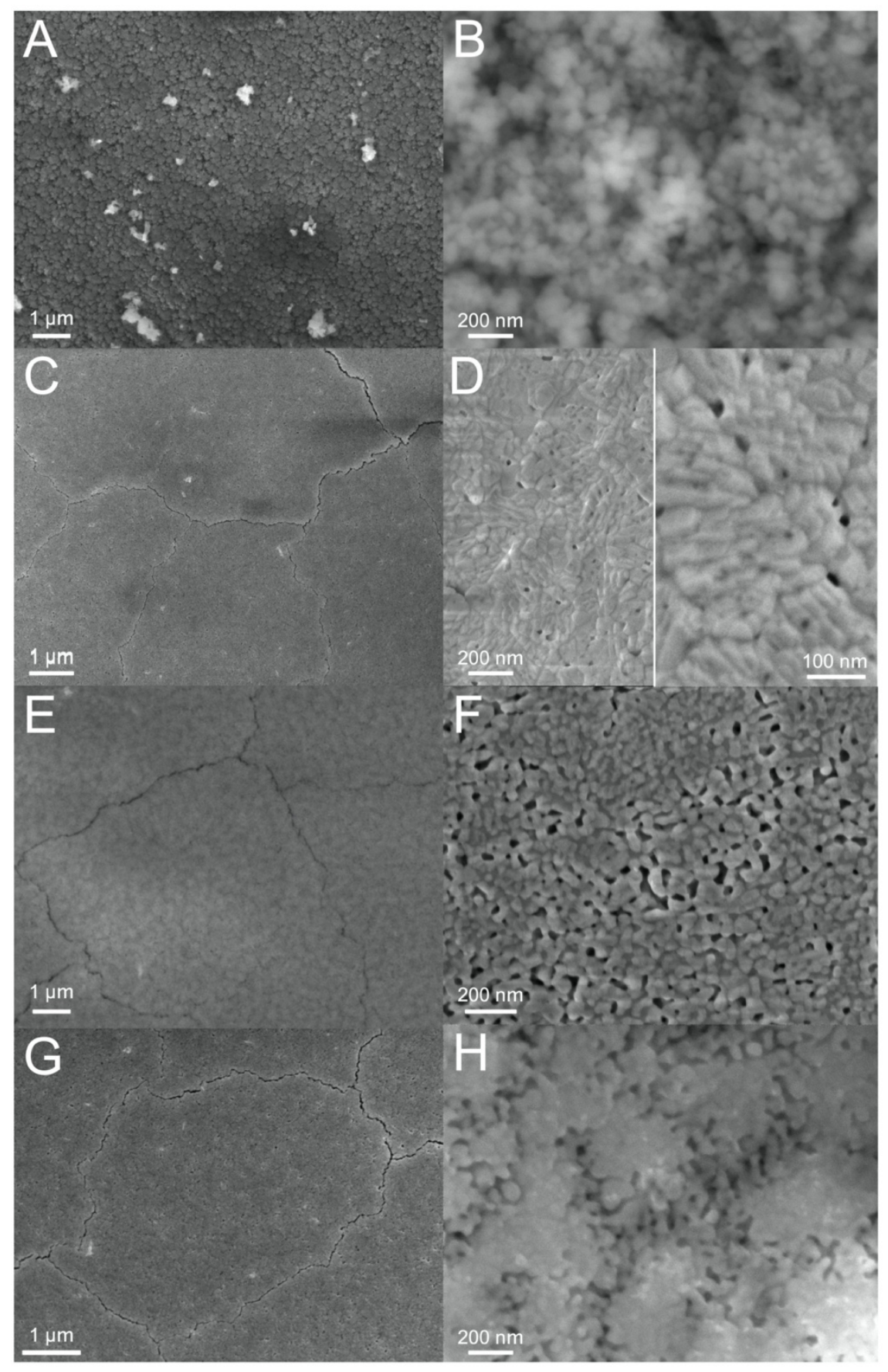

Figure 2: SEM images of (A-B) the bare $\beta$-SiC foam, (C-D) the $\mathrm{LFO} / \beta-\mathrm{SiC}$ foam with 10 wt.\% of LFO, (E-F) the P25-LFO/ $\beta-\mathrm{SiC}$ foam and (G-H) the SG-LFO/ $\beta-\mathrm{SiC}$ foam.

SEM characterization evidenced the change in surface morphology upon the implementation of the sol-gel Pechini synthesis directly on the granular (porous) surface of the thermally-treated $\beta$-SiC foams (Figure 2A,B vs. 2C-H). It confirms the 
homogeneous nature of the LFO-based coating at the surface of the foams at the micronscale (Figure 2A,C,E,G). A closer look reveals that the porosity of the LFO coating increased upon the introduction of titanium into it (Figure 2D,F,H), in agreement with the $\mathrm{N}_{2}$ sorption study. Indeed, while the coverage of the support by the LFO coating is accompanied by a reduction of the specific surface area from 16.2 to $11.3 \mathrm{~m}^{2} / \mathrm{g}$ for a LFO content of $10 \mathrm{wt} . \%$, with a concomitant decrease in porosity (Table 1, Figure S2), a slight increase in both surface area (to ca. 13.2-14.6 $\mathrm{m}^{2} / \mathrm{g}$ ) and pore volume was observed for the Ti-LFO/ $\beta$-SiC foams.

Fig. 3 shows the XRD patterns of the bare $\beta$-SiC foam support and of the different $\beta$-SiC foam supported LFO-based catalysts. In addition to the diffraction lines corresponding to the (111), (200), (202), (311) and (222) planes of the fcc structure $\beta$ SiC polymorph (JCPDS card 03-065-0360) ${ }^{48}$, all the patterns can be indexed to the Pbnm orthorhombic unit cell of $\mathrm{LaFeO}_{3}$ (JCPDS card 070-7777), independently of the presence of titanium and of the titanium source, similarly to what was observed for the pristine and Ti-modified $\mathrm{LaFeO}_{3}$ powders ${ }^{10}$. No single oxide phase is observed, and the mean crystallite size of the supported LFO-based phase is not influenced by the introduction of titanium during the sol-gel Pechini synthesis, with values within the $21-25 \mathrm{~nm}$ range. However, in the case of Ti-modified samples, the low weight fraction of the LFO phase in comparison to the $\beta$-SiC support (10 wt.\%), combined to the low content of titanium introduced during the Pechini synthesis, made ineffective any Rietveld refinement, in contrary to our previous works on the analogous bulk Ti-LFO powders ${ }^{8}$. 


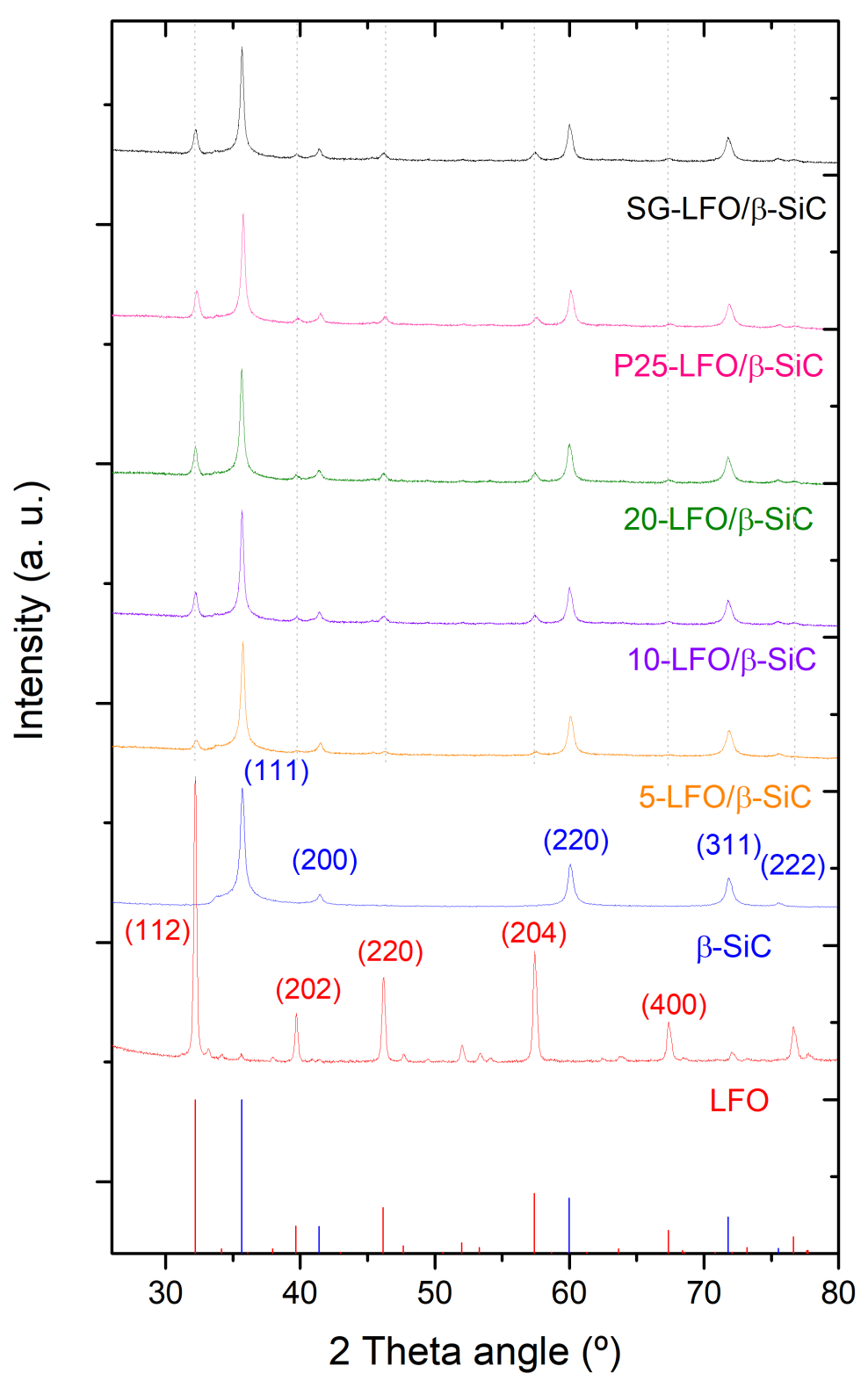

Figure 3: XRD patterns of the bare $\beta$-SiC foam support and of the different $\beta$-SiC foam supported LFO-based catalysts. Reflections are assigned to both LFO and $\beta$-SiC phases using 070-7777 and 03-065-0360 JCPDS cards, respectively.

By contrast, even though a complete structural refinement with cationic site occupation was not possible, advanced XRD recording (details in Supporting Information SI2) allowed us to evidence a significant change in the Pbnm orthorhombic unit cell parameters of LFO upon modification of the synthesis by titanium. Consequently, in 
comparison to the LFO unit cell, the change in the cell parameters from $a, b, c=5.547(1)$, 5.560(1), 7.861(1) for the SG-LFO/ $\beta-\mathrm{SiC}$ foam catalyst to $a, b, c=5.536(1), 5.564(1)$, 7.875(1) for its non-modified counterpart indicates the insertion of Ti within the structure, by analogy to what was previously observed in the case of LFO powders (Figure S3). However, even with this setup, the determination of the cationic distribution proved unsuccessful, in contrary to the analogous study performed on LFO powders, that proved the partial $\mathrm{La} \rightarrow \mathrm{Ti}$ substitution with a $11 \%$ rate ${ }^{10}$. Therefore, the theoretical variation of the peak intensities was computed for characterizing the detectability and the sensitivity to structural Ti of some selected characteristic (hkl) Bragg peaks of the LFO phase, as shown in Figures S4A and S4B. The results clearly show that the most sensitive peak to the insertion of titanium is the (110), while the other peaks have either a too low intensity (e.g. 111) or a too low relative variation (i.e.,sensitivity, e.g. 220). In the case of a bulk LFO sample, the relative strength of the (110) peak is ca. $15 \%$ with a computed sensitivity of ca. $35 \%$ when $20 \%$ of $\mathrm{Ti}$ is inserted. Taking this into account, the normalized intensity variation of the (110) peak of LFO expressed here relative to the (111) peak of $\beta$-SiC (i.e. the most intense peak) has been computed for a sample consisting in a $\mathrm{SiC}$ matrix with $12 \%$ of LFO (Figure S4C). It demonstrates that, for the expected $\mathrm{Ti} \rightarrow$ La substitution degree of $11 \%$ (by analogy with the study with powders) - and even for a substitution degree computed at $25 \%$-, the insertion of Ti into the LFO structure results in a variation of a few thousandths of the measured intensity. Such tiny variations cannot be detected with a conventional diffractometer and would require the use of a synchrotron facility.

The structural analogy between both powdery SG-LFO and $\beta$-SiC foam supported SG-LFO catalysts was supported by the XPS investigations. Indeed, although much lower signal intensities were recorded due to the presence of the $\beta$-SiC matrix, the core orbital XPS spectra demonstrate the presence of $\mathrm{La}^{3+}, \mathrm{Fe}^{3+}$ and $\mathrm{Ti}^{3+}$ cations at the surface of the 
supported SG-LFO catalyst, like its bulk SG-LFO counterpart (Figure S5) ${ }^{10}$. Independently of the catalyst form, similar binding energies were recorded for the different orbital doublet contributions, in agreement with a formal +3 oxidation state within a $\mathrm{ABO}_{3}$ structure ${ }^{49-53}$. 
Table 1. Some physico-chemical properties of the bare $\beta$-SiC foam support and of the different $\beta$-SiC foam supported LFO-based catalysts.

\begin{tabular}{|c|c|c|c|c|c|c|c|}
\hline & $\beta-\mathrm{SiC}$ & $5-\mathrm{LFO} / \beta-\mathrm{SiC}$ & $10-\mathrm{LFO} / \beta \mathrm{SiC}$ & $20-\mathrm{LFO} / \beta-\mathrm{SiC}$ & $\mathrm{P} 25-\mathrm{LFO} / \beta-\mathrm{SiC}$ & $\mathrm{SG}-\mathrm{LFO} / \beta-\mathrm{SiC}$ & $\mathrm{LFO}^{\mathrm{b}}$ \\
\hline wt. $\%$ content of LFO & - & 5 & 10 & 20 & 10 & 10 & - \\
\hline $\begin{array}{l}\text { BET specific surface } \\
\text { area }\left(\mathrm{m}^{2} / \mathrm{g}\right)\end{array}$ & 16.2 & - & 11.3 & - & 13.2 & 14.6 & 8 \\
\hline $\begin{array}{l}\text { LFO mean crystallite } \\
\text { size }(\mathrm{nm})^{\mathrm{a}}\end{array}$ & - & 25 & 24 & 25 & 21 & 23 & 46 \\
\hline Pore volume $(\mathrm{mL} / \mathrm{g})$ & 0.107 & - & 0.081 & - & 0.090 & 0.096 & 0.014 \\
\hline
\end{tabular}

a determined from the XRD analysis by applying the Scherrer equation to the three main diffraction peaks of the $\mathrm{LaFeO}_{3}$ structure (JCPDS Card 070-7777), with the classical assumption of spherical crystallites, taking into account the intrinsic broadening of the peaks due to the instrumentation.

${ }^{\mathrm{b}}$ bulk powder LFO prepared following the Pechini sol-gel synthesis described in Supporting Information (Figure S7) and in ${ }^{9}$. 
Table 2. Kinetic rate constants of $\mathrm{H}_{2} \mathrm{O}_{2}$ decomposition, 4-CP oxidation and mineralization, through the combined photo-CWPO and photocatalysis AOPs. Fe leached at $180 \mathrm{~min}$ and TOC conversion at $180 \mathrm{~min}$. Conditions: $[4-\mathrm{CP}]_{0}=25 \mathrm{mg} / \mathrm{L} ;\left[\mathrm{H}_{2} \mathrm{O}_{2}\right]_{0}=125 \mathrm{mg} / \mathrm{L} ; \mathrm{T}=25^{\circ} \mathrm{C} ; \mathrm{UV}-\mathrm{A}$ irradiance of $60 \mathrm{~W}$ m ${ }^{-2}$.

\begin{tabular}{|c|c|c|c|c|c|c|}
\hline Catalyst & $\mathrm{k}^{\prime}{ }_{4-\mathrm{CP}}\left(\mathrm{min}^{-1}\right)$ & $\mathbf{k}_{1}{ }^{\prime}$ тос $(\mathbf{m g} / \mathbf{L m i n})^{\mathrm{a}}$ & $\mathbf{k}_{2}{ }^{\prime}$ тоС $(\mathbf{m g} / \mathbf{L m i n})^{\text {b }}$ & $\mathrm{k}_{\mathrm{H} 2 \mathrm{O} 2}^{\prime}\left(\mathrm{min}^{-1}\right)$ & $\mathbf{X}_{\mathrm{TOC}}(\%)$ & $\mathrm{Fe}_{\text {leached }}(\mathrm{mg} / \mathrm{L})$ \\
\hline $5-\mathrm{LFO} / \beta-\mathrm{SiC}$ & 0.019 & 0.061 & & $\mathrm{c}$ & 47 & $0.8^{\mathrm{d}}$ \\
\hline $10-\mathrm{LFO} / \beta-\mathrm{SiC}$ & 0.039 & 0.182 & 0.020 & $\mathrm{c}$ & 90 & 2.5 \\
\hline $20-\mathrm{LFO} / \beta-\mathrm{SiC}$ & 0.034 & 0.171 & & $\mathrm{c}$ & 91 & 1.8 \\
\hline $\mathrm{P} 25-\mathrm{LFO} / \beta-\mathrm{SiC}$ & 0.019 & 0.078 & 0.021 & 0.019 & 71 & 0.05 \\
\hline $\mathrm{SG}-\mathrm{LFO} / \beta-\mathrm{SiC}$ & 0.036 & 0.137 & 0.023 & 0.035 & 100 & $<0.001$ \\
\hline $1-4 \#$ reuse of $S G-L F O / \beta-S i C$ & $0.036 \pm 0.001$ & $0.138 \pm 0.004$ & $0.023 \pm 0.001$ & & $100^{\mathrm{e}}$ & $<0.001$ \\
\hline
\end{tabular}

${ }^{\text {a }}$ apparent kinetic rate constant attributed to the initial photo-CWPO/photocatalytic combined process

${ }^{b}$ apparent kinetic rate constant attributed to the pure photocatalytic reaction after complete $\mathrm{H}_{2} \mathrm{O}_{2}$ depletion

${ }^{c}$ it must be said that the progressive increase in the active $\mathrm{Fe}$ ion concentration in the solution made a pseudo first order kinetic law for the $\mathrm{H}_{2} \mathrm{O}_{2}$ decomposition inapplicable, as the first order apparent kinetic rate constant is linearly depending on the homogeneous (released) Fe ion concentration, that cannot be considered as constant during the test.

$\mathrm{d}[\mathrm{Fe}]$ after $360 \mathrm{~min}$ of test

${ }^{\text {e }} \mathrm{X}_{\text {TOC }}$ after 180 min was $96 \%$ for the test $\# 4$ 


\subsection{Catalytic activity}

\subsubsection{Optimization of the catalyst concentration on the $\beta-\mathrm{SiC}$ foam}

In a first step, the non-modified $\mathrm{LaFeO}_{3}$ material was used as reference catalyst for optimizing the amount of catalyst immobilized on the foam surface in terms of activity in the combined photo-CWPO/photocatalysis process and the evolution with time under irradiation of the main features followed during the reaction is depicted in Fig. 4. First, uncoated $\beta$-SiC foams does not reveal any catalytic activity under UV-A light, neither in the presence or absence of $\mathrm{H}_{2} \mathrm{O}_{2}$ as oxidant. Independently of the LFO content, the $\beta$-SiC supported LFO catalysts displayed the ability to decompose $\mathrm{H}_{2} \mathrm{O}_{2}$ in a typical photoFenton reaction. The low-loaded 5-LFO/ $\beta-\mathrm{SiC}$ catalyst led to a total depletion of $\mathrm{H}_{2} \mathrm{O}_{2}$ in $240 \mathrm{~min}$, with a quasi-complete 4-CP degradation and a mineralization degree of $68 \%$ after $360 \mathrm{~min}$ of reaction. Both the $10-\mathrm{LFO} / \beta-\mathrm{SiC}$ and $20-\mathrm{LFO} / \beta-\mathrm{SiC}$ catalysts decomposed $\mathrm{H}_{2} \mathrm{O}_{2}$ faster than their 5-LFO/ $\beta$-SiC counterpart, so that complete $\mathrm{H}_{2} \mathrm{O}_{2}$ decomposition was achieved after 120 min of test in both cases. This faster decomposition correlated with both faster degradation and mineralization of 4-CP observed for both catalysts, and complete 4-CP degradation was obtained after about $150 \mathrm{~min}$, while a TOC conversion of about $90 \%$ was achieved after $180 \mathrm{~min}$.

Whatever the LFO content, the LFO/ $\beta$-SiC foam catalysts suffered from a strong release of iron to the solution, within the $0.8-2.5 \mathrm{mg} / \mathrm{L}$ range depending on the content of active phase. The low stability of the supported LFO catalyst is in agreement with the behaviour of LFO powders previously used as suspensions in batch reactors in the combined photo-CWPO/photocatalysis process ${ }^{10}$. As a result of the low stability of the LFO catalyst, the leached iron can contribute significantly to the process activity through

a typical homogeneous photo-Fenton mechanism. Consequently, the concentration 
profiles and the apparent kinetic rate constants reported in Figure 4 and in Table 2, respectively, can not only be attributed to pure heterogeneous reactions.
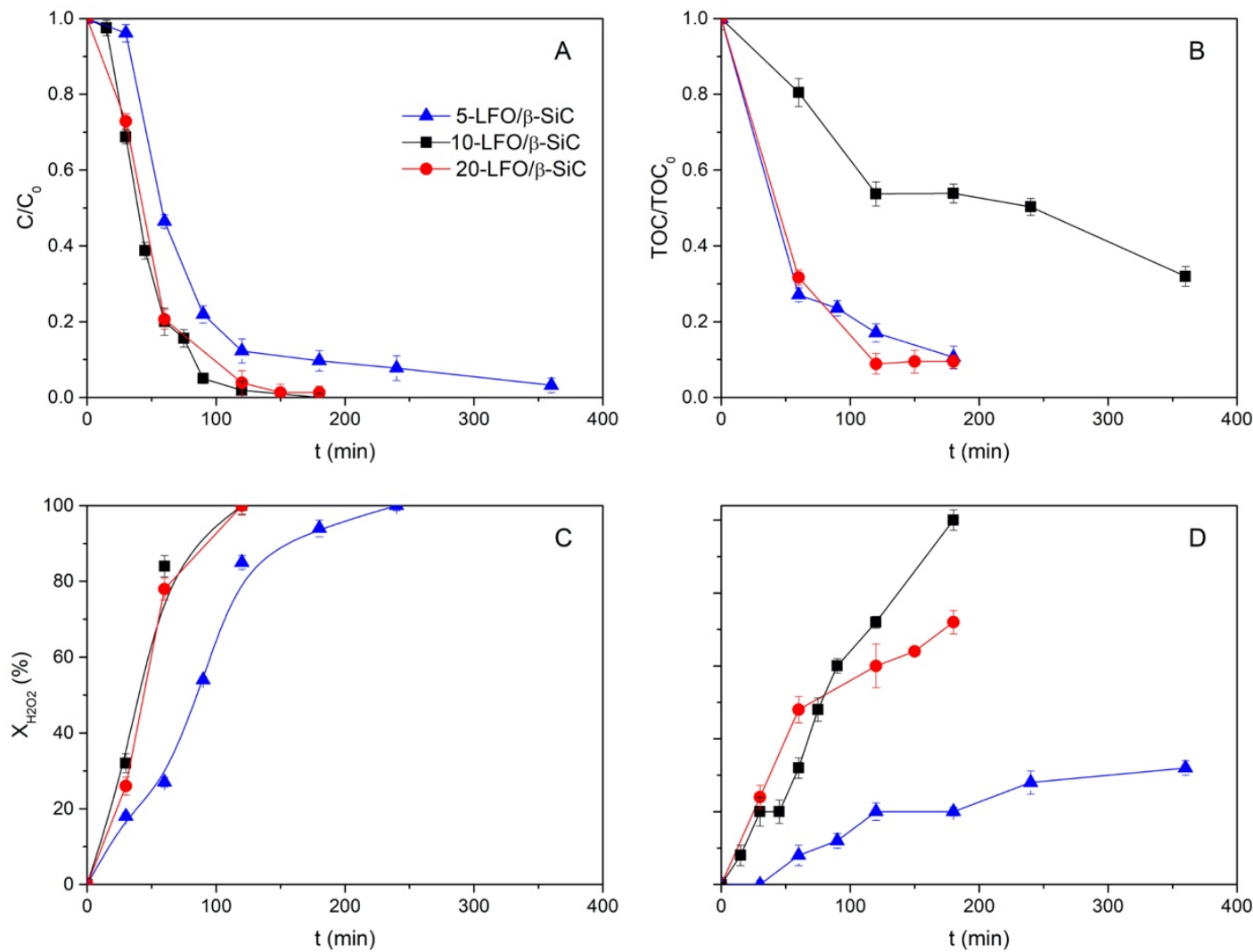

Figure 4: Evolution with time under irradiation of (A) the relative 4-CP concentration, (B) the relative TOC concentration, (C) the $\mathrm{H}_{2} \mathrm{O}_{2}$ decomposition yield and (D) the concentration of leached $\mathrm{Fe}$ in the solution, during the combined photo-CWPO and photocatalytic degradation of 4-CP over the LFO/ $\beta-\mathrm{SiC}$ foam catalysts with a LFO wt. content of 5, 10 and 20\%. Conditions: $[4-\mathrm{CP}]_{0}=25 \mathrm{mg} / \mathrm{L} ;\left[\mathrm{H}_{2} \mathrm{O}_{2}\right]_{0}=125 \mathrm{mg} / \mathrm{L} ; \mathrm{T}=25^{\circ} \mathrm{C}$; UV-A irradiance of $60 \mathrm{~W} \mathrm{~m}^{-2}$.

The iron released to the solution is proposed to be responsible for the incomplete mineralization of the 4-CP substrate, as often reported for CWPO reactions ${ }^{54,55}$. Indeed, 
iron in solution is prone to form highly stable Fe complexes by reaction with the latest intermediates like short-chain carboxylic acids (oxalic, formic or acetic acids). The very slow photodegradation ability of those complexes inhibits the conversion of the late intermediates by stopping the iron redox cycle, and consequently does not allow complete mineralization of the substrate to be achieved despite total $\mathrm{H}_{2} \mathrm{O}_{2}$ depletion (Eq. (1)) ${ }^{55-57}$.

$$
\left[\mathrm{Fe}^{3+}\left(\mathrm{RCOO}^{-}\right)\right]^{2+} \stackrel{h v}{\rightarrow} \mathrm{Fe}^{2+}+\mathrm{CO}_{2}+\mathrm{R}
$$

The influence of the LFO content on the characteristic apparent kinetic rate constants is summarized in Figure 5, considering a pseudo first order reaction for the 4-CP degradation and a zero order reaction for the TOC conversion as usual in photoassisted processes. The evolution of both rate constants follows a similar behavior, with a first linear increase with increasing the LFO loading on the $\beta$-SiC foam before achieving a simili plateau. This behavior is similar to that observed in pure photocatalysis using alveolar foams as support for $\mathrm{TiO}_{2}$ in gas- and liquid-phase applications, independently of the $\mathrm{TiO}_{2}$ nature, of the immobilization process and of the photonic flux, ${ }^{11,14,18,58}$ i.e., a first increase in the amount of illuminated particles and subsequently a screening effect of excess particles. Although less studied, the rate profiles observed in heterogeneous Fenton-like processes usually evidence a first increase with the Fe content, while too high contents are counterproductive, due usually to the suspension turbidity that reduces the light penetration to the reactor core, and/or to the scavenging of excess $\mathrm{Fe}$ by $\mathrm{OH}^{\circ} 59,60$.

Obviously, it must be said that the rate constants cannot be entirely related to the activity of the $\beta$-SiC foam-based catalysts, as those constants contain an homogeneous contribution due to the presence of iron in solution. However, the $10-\mathrm{LFO} / \beta-\mathrm{SiC}$ foam catalyst can be considered as optimized in terms of amount of active phase immobilized on the structured support, i.e. $10 \mathrm{wt} . \%$, with apparent rate constants of $0.039 \mathrm{~min}^{-1}$ and 
$0.182 \mathrm{mgL}^{-1} \mathrm{~min}^{-1}$ for 4-CP degradation and TOC conversion, respectively. This agrees with the optimal wt. $\%$ contents of $10-15 \%$ reported for $\mathrm{TiO}_{2} / \beta-\mathrm{SiC}$ foam photocatalysts, that slightly varied depending on the application and the kind of $\mathrm{TiO}_{2}{ }^{11,18,58}$. It must be said that the progressive increase in the Fe concentration in the solution made a pseudo first order kinetic model for $\mathrm{H}_{2} \mathrm{O}_{2}$ decomposition inapplicable, as the first order apparent kinetic rate constant depends linearly on the homogeneous (released) Fe concentration, that cannot be considered here as constant during the test. ${ }^{61}$ Unlike the powdery catalysts in batch mode, for which this effect can be most of the time neglected, this deviation from the pseudo first order kinetic law is particularly marked when using immobilized catalysts that have reduced activity in comparison to their powdery counterparts.

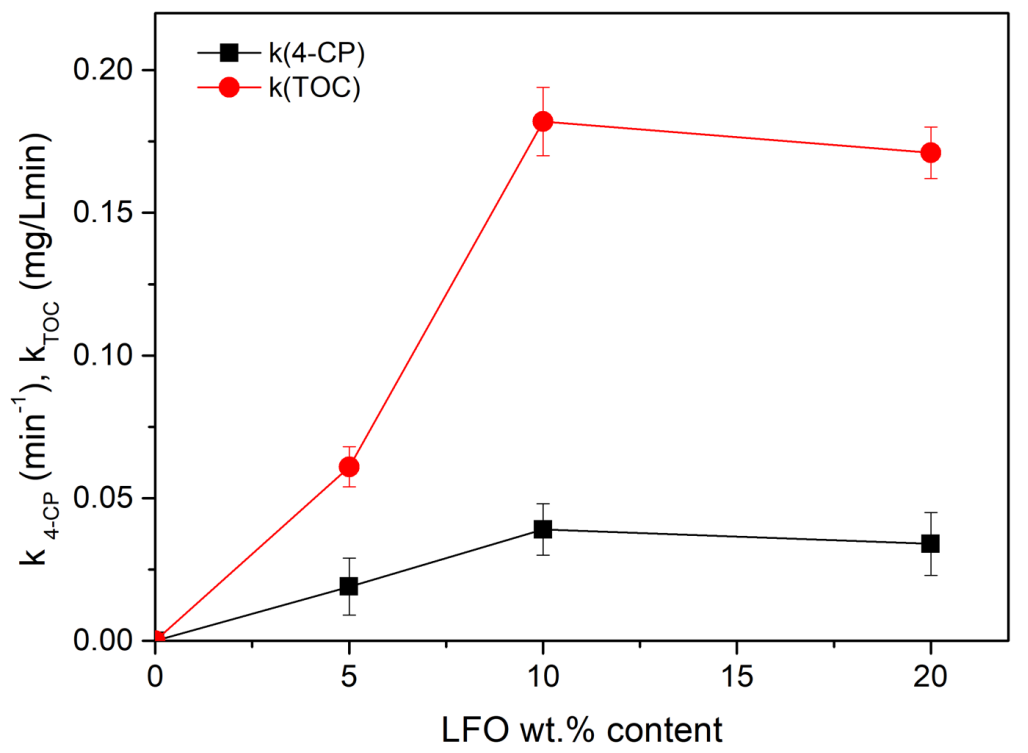

Figure 5: Influence of the LFO content in the LFO/ $\beta$-SiC foam catalyst on the kinetic rate constants of 4-CP oxidation and mineralization through the combined photo-CWPO and photocatalysis AOPs. Conditions: $[4-\mathrm{CP}]_{0}=25 \mathrm{mg} / \mathrm{L} ;\left[\mathrm{H}_{2} \mathrm{O}_{2}\right]_{0}=125 \mathrm{mg} / \mathrm{L} ; \mathrm{T}=25^{\circ} \mathrm{C}$; UV-A irradiance of $60 \mathrm{~W} \mathrm{~m}^{-2}$. 


\subsubsection{Pure photocatalysis on $\mathrm{LaFeO}_{3} / \beta-\mathrm{SiC}$ foams}

Once the optimal load of the catalyst on the $\beta$-SiC foam was determined, the activity of the unmodified and Ti-modified LFO/ $\beta$-SiC foam catalysts in pure photocatalysis is reported in Figure 6. As expected because of the lower irradiated surfaces exposed by the alveolar foam, the immobilized catalysts display a reduced photoactivity in comparison to their powdery counterparts in slurry mode ${ }^{10}$, with $4-\mathrm{CP}$ conversions remaining lower than $15 \%$ after 180 min of test. However, the incorporation of titanium within the LFO network leads to a faster 4-CP degradation, as evidenced by the increase in the apparent kinetic rate constants from $5 \times 10^{-4} \mathrm{~min}^{-1}$ for the non-modified $\mathrm{LFO} / \beta-\mathrm{SiC}$ foam up to 7 x $10^{-4} \mathrm{~min}^{-1}$ and $8 \times 10^{-4} \mathrm{~min}^{-1}$ for the $\mathrm{P} 25-\mathrm{LFO} / \beta-\mathrm{SiC}$ and the $\mathrm{SG}-\mathrm{LFO} / \beta-\mathrm{SiC}$ foam catalysts, respectively. Accordingly, the 4-CP conversion after $180 \mathrm{~min}$ increases from $6 \%$ to $11 \%$ and $14 \%$, respectively. This is accompanied by a slight improvement of the rate constant of 4-CP mineralization from $8 \times 10^{-4}$ to $3.1-4.1 \times 10^{-3} \mathrm{mgL}^{-1} \mathrm{~min}^{-1}$ for the Tisubstituted foam catalysts, although low TOC conversions of 5\% were achieved after 180 min of reaction in the best case. The enhancement of the reaction rates upon $\mathrm{Ti}$ substitution is similar to that observed on Ti-substituted LFO powders in the slurry mode. In the case of the powders, the superiority of $\mathrm{La}_{1-\mathrm{x}} \mathrm{Ti}_{\mathrm{x}} \mathrm{FeO}_{3}$ in pure photocatalysis was associated to the enhanced availability of the photogenerated charge carriers, as evidenced by fluorescence analysis ${ }^{10}$. It must be stressed that the low reaction rates and the low TOC conversions confirm that pure photocatalytic reaction as single mineralization process does not contribute significantly to the high initial reaction rates observed in the combined AOPs process. 


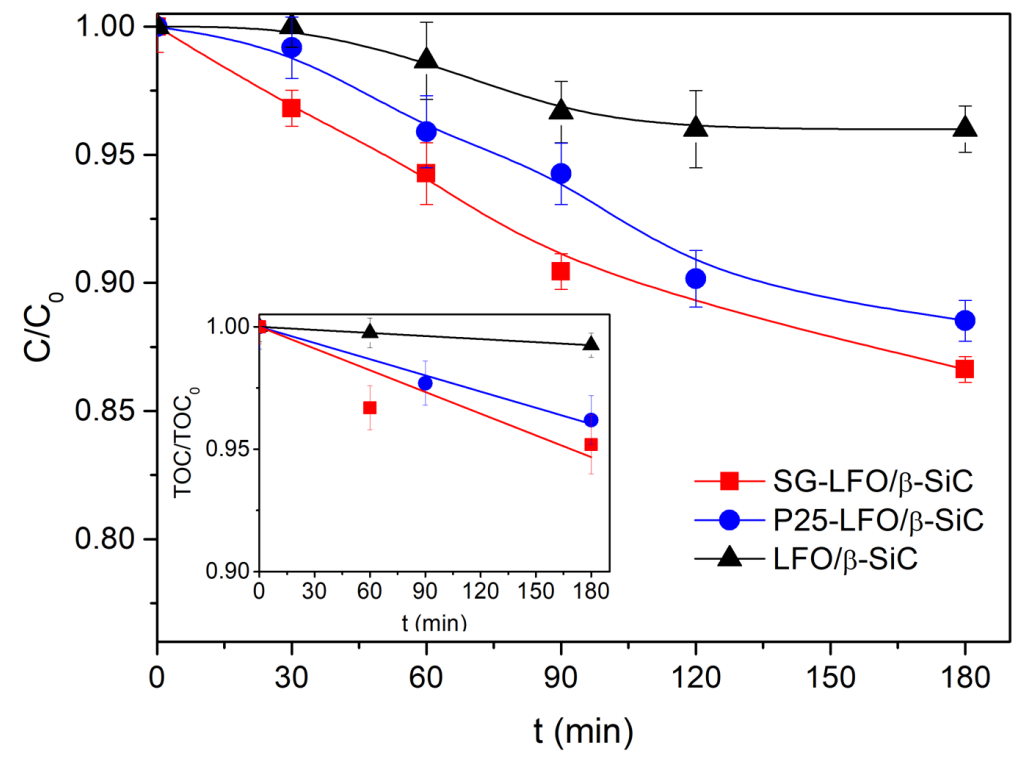

Figure 6: Time-evolution of both the $\mathrm{C} / \mathrm{C}_{0}$ and $\mathrm{TOC} / \mathrm{TOC}_{0}$ relative concentrations during the pure photocatalytic degradation of $4-\mathrm{CP}$ over the pristine $10-\mathrm{LFO} / \beta-\mathrm{SiC}$ foam and the Ti-modified LFO/ $\beta$-SiC foam catalysts. Conditions: $[4-\mathrm{CP}]_{0}=25 \mathrm{mg} / \mathrm{L} ; \mathrm{T}=25^{\circ} \mathrm{C} ; \mathrm{UV}-\mathrm{A}$ irradiance of $60 \mathrm{~W} \mathrm{~m}^{-2}$.

\subsubsection{Activity of the Ti-modified $\mathrm{LaFeO}_{3} / \beta-\mathrm{SiC}$ foam catalyst in the combined process}

Figure 7 shows the evolution of both 4-CP and TOC relative concentrations, the $\mathrm{H}_{2} \mathrm{O}_{2}$ decomposition and the released iron concentration during the time-course of the combined photo-CWPO/photocatalysis process on both $\mathrm{P} 25-\mathrm{LFO} / \beta-\mathrm{SiC}$ and $\mathrm{SG}-\mathrm{LFO} / \beta-$ $\mathrm{SiC}$ foam catalysts, compared to the $\mathrm{LFO} / \beta-\mathrm{SiC}$ foam. For both $\mathrm{Ti}-\mathrm{LFO} / \beta-\mathrm{SiC}$ foam catalysts, the introduction of titanium atoms within the network of the $\mathrm{LaFeO}_{3}$ phase results in a strong improvement of the robustness of the $\beta$-SiC foam supported catalyst by more than three orders of magnitude (Figure 7D). The concentration of the released iron in solution drastically decreases from $2.5 \mathrm{mgL}^{-1}$ in the case of the $\mathrm{LFO} / \beta-\mathrm{SiC}$ foam catalyst down to the negligible level of $0.05 \mathrm{mgL}^{-1}$ and further down to a non-detectable 
level (below $0.001 \mathrm{mgL}^{-1}$, i.e. corresponding to $0.00008 \%$ relative to the iron inside the LFO structure) for the $\mathrm{P} 25-\mathrm{LFO} / \beta-\mathrm{SiC}$ and $\mathrm{SG}-\mathrm{LFO} / \beta$-SiC foam catalysts, respectively. This stability increase of the immobilized $\beta$-SiC foam catalysts is similar to that observed with the powdery LFO catalysts upon $\mathrm{Ti} \rightarrow$ La cationic substitution, in both cases the stability enhancement being greater with amorphous dried titania as titanium source than with crystallized Aeroxide P25 ${ }^{10}$.
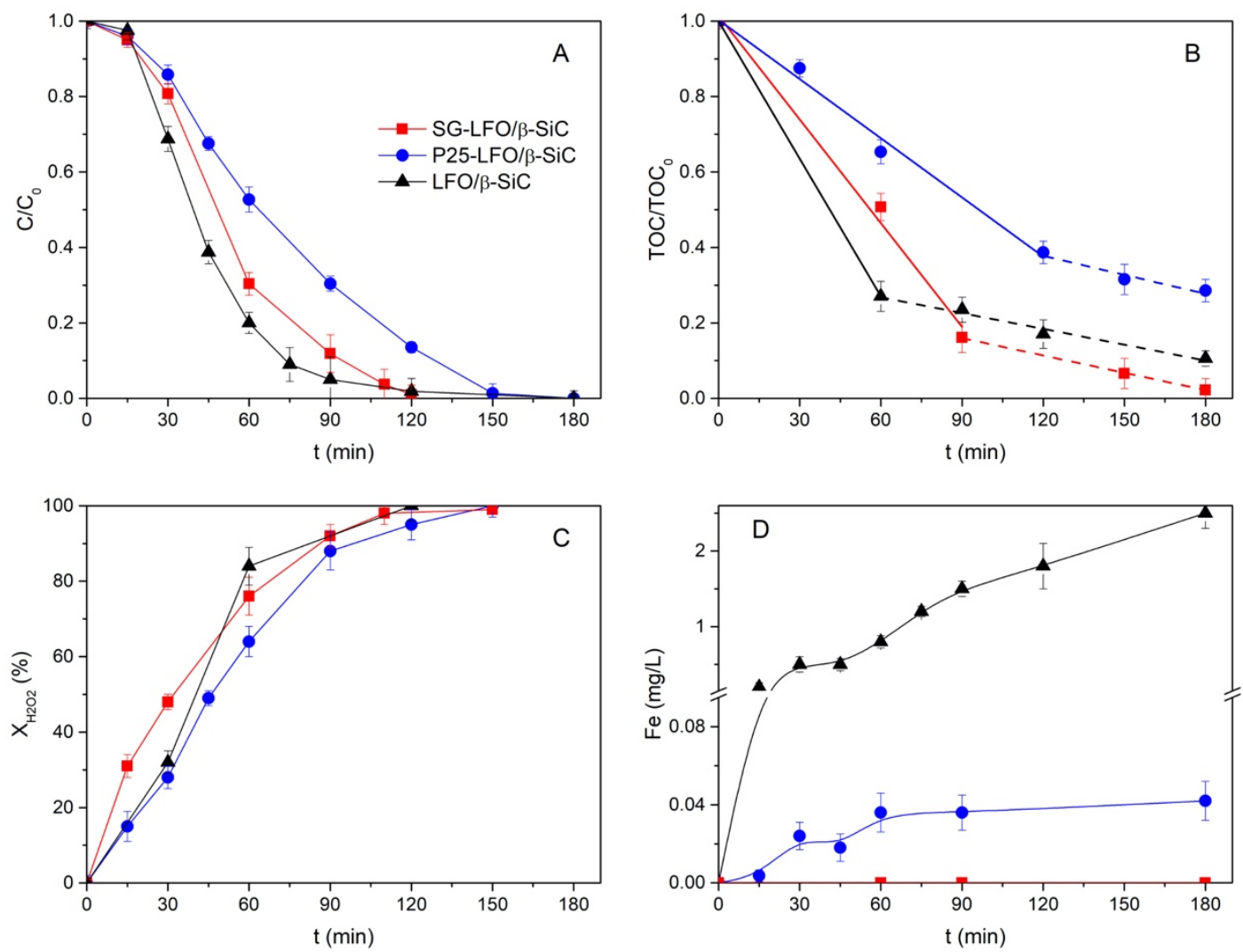

Figure 7: Evolution with irradiation time of (A) the relative 4-CP concentration, $(\mathbf{B})$ the relative TOC concentration, (C) the $\mathrm{H}_{2} \mathrm{O}_{2}$ decomposition yield and (D) the concentration of leached $\mathrm{Fe}$ in the solution, during the combined photo-CWPO and photocatalytic degradation of $4-\mathrm{CP}$ over the pristine and the Ti-modified LFO/ $\beta$-SiC foam catalysts. Conditions: $[4-\mathrm{CP}]_{0}=25 \mathrm{mg} / \mathrm{L} ;\left[\mathrm{H}_{2} \mathrm{O}_{2}\right]_{0}=125 \mathrm{mg} / \mathrm{L} ; \mathrm{T}=25^{\circ} \mathrm{C}$; UV-A irradiance of $60 \mathrm{~W}$ $\mathrm{m}^{-2}$. 
In contrary to the un-modified $\mathrm{LFO} / \beta$-SiC foam, the drastic enhancement of the catalyst robustness observed for the $\mathrm{SG}-\mathrm{LFO} / \beta-\mathrm{SiC}$ foam, and the absence of any detectable $\mathrm{Fe}$ in solution, demonstrate that the $\mathrm{SG}-\mathrm{LFO} / \beta-\mathrm{SiC}$ foam catalyst operates through pure heterogeneous surface reactions without any homogeneous contribution. Consequently, here the apparent kinetic rate constants for $\mathrm{H}_{2} \mathrm{O}_{2}$ decomposition and for 4$\mathrm{CP}$ and TOC conversion are ascribed to purely heterogeneous surface mechanisms. The times required for the complete abatement are $150 \mathrm{~min}$ with $\mathrm{P} 25-\mathrm{LFO} / \beta-\mathrm{SiC}$ and $120 \mathrm{~min}$ with SG-LFO/ $\beta-\mathrm{SiC}$, with 4-CP oxidation rates of $0.019 \mathrm{~min}^{-1}$ and $0.036 \mathrm{~min}^{-1}$, respectively. Figure $7 \mathrm{~B}$ reveals the existence of two consecutive mineralization rates, no matter the supported LFO phase was modified or not with titanium; the first one is attributed to the initial combined photo-CWPO/photocatalytic reaction with fast apparent kinetic rate constants, while the second contribution, slower, is ascribed to pure photocatalysis after almost complete $\mathrm{H}_{2} \mathrm{O}_{2}$ depletion. The initial apparent kinetic constants with Ti-modified $\mathrm{LFO} / \beta-\mathrm{SiC}$ foams are lower than that obtained with the $\mathrm{LFO} / \beta-\mathrm{SiC}$ foam, probably because they do not contain any homogeneous contribution. Independently of the titanium incorporation, the $\beta$-SiC foam supported catalysts display a similar apparent kinetic constant in the second part of the process, at about $0.021 \pm$ $0.002 \mathrm{mgL}^{-1} \mathrm{~min}^{-1}$, with no significant differences in terms of activity. As a result, the SG$\mathrm{LFO} / \beta-\mathrm{SiC}$ foam catalyst reaches complete 4-CP mineralization within 180 min with no release of $\mathrm{Fe}$ to the solution operating through a fully heterogeneous process.

The enhancement of both performance and robustness of the catalyst upon the modification by titanium of the immobilized LFO catalyst, together with the Ti-modified $\mathrm{LaFeO}_{3}$ catalyst characterization results, support the hypothesis that implementing the titanium-modified Pechini sol-gel synthesis in-situ at the surface of the $\beta$-SiC foam allows 
to preparing highly efficient $\mathrm{La}_{1-x} \mathrm{Ti}_{x} \mathrm{FeO}_{3}$ dual catalysts with combined heterogeneous photo-Fenton and photocatalytic activity, as in the case of the bulk powder catalyst counterparts. It can in consequence be hypothesized that the optimized SG-LFO catalyst immobilized on the $\beta$-SiC foams possesses a Ti content of $c a .4$ at. $\%$ by analogy with its powdery counterpart. Therefore, the performance improvement upon titanium modification of the immobilized $\mathrm{LaFeO}_{3}$ catalyst is proposed here to find its origin in the same phenomena than for powdery catalysts. It is consequently attributed to both the enhanced availability of the photogenerated charge carriers at the surface and the electronic enrichment of the surface Fe upon the partial $\mathrm{Ti} \rightarrow \mathrm{La}$ substitution, as evidenced by both fluorescence and surface analysis ${ }^{10}$. The enhanced availability of the photogenerated charge carriers is proposed to allow a faster decomposition of $\mathrm{H}_{2} \mathrm{O}_{2}$ to $\mathrm{HO}^{\circ}{ }_{\mathrm{x}}$ radicals (Eqs. 2-4), and a more efficient generation of $\mathrm{OH}^{\circ}$ radicals from adsorbed water (Eq. 5).

$$
\begin{aligned}
& \mathrm{La}_{1-x} \mathrm{Ti}_{x} \mathrm{FeO}_{3} \stackrel{h v}{\rightarrow} e^{-}+h^{+} \\
& e^{-}+\mathrm{H}_{2} \mathrm{O}_{2} \rightarrow \mathrm{HO}^{\circ}+\mathrm{OH}^{-} \\
& h^{+}+\mathrm{H}_{2} \mathrm{O}_{2} \rightarrow \mathrm{HOO}^{\circ}+\mathrm{H}^{+} \\
& h^{+}+\mathrm{H}_{2} \mathrm{O} \rightarrow \mathrm{HO}^{\circ}+\mathrm{H}^{+}
\end{aligned}
$$

The combined AOPs-induced synergy enables the immobilized $\mathrm{La}_{1-\mathrm{x}} \mathrm{Ti}_{\mathrm{x}} \mathrm{FeO}_{3}$ dual catalyst (i) to operate mainly as photo-CWPO catalyst at the beginning of the process, so that high reaction rates can be obtained, and (ii) to act as photocatalyst for mineralizing the short chain carboxylic acids and in consequence for hindering the formation of stable 
Fe complexes responsible for the slower kinetics and the catalyst deactivation observed in pure Fenton-like processes.

Table 3. Photonic efficiencies for mineralization and degradation of 4-CP obtained with the different catalysts and processes.

\begin{tabular}{ccccc}
\hline \multicolumn{1}{c}{ Catalyst } & Process & $\mathbf{t}_{\text {miner }}(\mathbf{m i n})$ & $\boldsymbol{\xi}_{4-\mathrm{CP}}(\%)$ & $\xi_{\text {TOC }}(\%)$ \\
\hline \multirow{2}{*}{ SG-LFO/ $\beta-\mathrm{SiC}$} & Dual & 180 & 9.38 & 37.6 \\
& Photocatalysis & $6097^{\mathrm{a}}$ & 0.21 & 1.11 \\
$\mathrm{P} 25-\mathrm{LFO} / \beta-\mathrm{SiC}$ & Dual & $300^{\mathrm{b}}$ & 4.95 & 22.6 \\
& Photocatalysis & $8064^{\mathrm{b}}$ & 0.18 & 0.84 \\
$\mathrm{P} 25 / \beta-\mathrm{SiC}$ & Photocatalysis & $463^{\mathrm{c}}$ & 5.13 & 14.6 \\
\hline
\end{tabular}

a extrapolated from Figure 6 and from the associated apparent kinetic rate constant

${ }^{b}$ extrapolated from Figure 7 and from the associated apparent kinetic rate constants shown in Table 2

c TOC evolution curve for the P25/ $\beta$-SiC foam shown in Figure S6

Table 3 collects the $\xi$ photonic efficiencies obtained for both 4-CP degradation and mineralization for the different catalysts and the two types of reaction (dual photoCWPO/photocatalysis and pure photocatalysis). Given the impossibility of determining all the reaction intermediates and, hence, of knowing the number of holes consumed in the oxidation reactions at any reaction time, the time needed for total mineralization was extrapolated in the cases where total mineralization $([\mathrm{TOC}]=0)$ was not achieved within the test duration, considering that the TOC disappearance rate follows zero-order kinetics and should therefore be independent of [TOC] throughout the reaction. The obtained 
efficiencies for pure photocatalytic reactions using $\mathrm{Ti}-\mathrm{LFO} / \beta-\mathrm{SiC}$ foams are in the range of previously reported values for 4-CP mineralization, ${ }^{62,63}$ with photonic efficiencies for degradation and mineralization of $4-\mathrm{CP}$ of about $0.2 \%$ and $1 \%$, respectively. ${ }^{39,57}$ By contrast, the photonic efficiency for 4-CP degradation strongly increases with the dual photo-CWPO/photocatalysis process, up to $9.38 \%$ and $4.95 \%$ for the $\mathrm{SG}-\mathrm{LFO} / \beta-\mathrm{SiC}$ and the $\mathrm{P} 25-\mathrm{LFO} / \beta-\mathrm{SiC}$ foam catalysts, respectively. Further, far higher photonic efficiencies for 4-CP mineralization are achieved using the dual catalysts, namely $37.6 \%$ and $22.6 \%$ for the SG-LFO $/ \beta-\mathrm{SiC}$ and the $\mathrm{P} 25-\mathrm{LFO} / \beta-\mathrm{SiC}$ foam catalysts, respectively, that in both cases strongly outperform the P25/ $\beta$-SiC foam reference value, i.e. $14.6 \%$.

The substitution of the suspended powdery catalyst in slurry mode by its $\beta$-SiC foam immobilized counterpart obviously results in a loss in efficiency of the combined photo$\mathrm{CWPO} /$ photocatalytic process for treating water. This can be quantified by defining an immobilization parameter, that normalizes the initial 4-CP mineralization rate obtained with the $\beta$-SiC foam supported catalyst relatively to that achieved using the suspended powdery counterpart. It must be said that this parameter is only relevant for rates associated to pure or quasi-pure heterogeneous surface reactions. Considering the water treatment efficiency in the slurry mode detailed in Garcia-Muñoz et al. ${ }^{10}$ and recalled in Supporting Information (Figure S7, Table S2), immobilization parameters of 0.49 and 0.43 were observed with $\mathrm{P} 25-\mathrm{LFO} / \beta-\mathrm{SiC}$ and $\mathrm{SG}-\mathrm{LFO} / \beta-\mathrm{SiC}$ catalysts, respectively. In the case of the $\mathrm{SG}-\mathrm{LFO} / \beta-\mathrm{SiC}$ catalyst, the immobilization parameter can also refer to the extension of the treatment duration necessary to achieve full 4-CP mineralization, from 90 min to 180 min upon immobilization, giving an immobilization parameter of 2 . Both parameters highlight that ca. $50 \%$ of the water treatment efficiency is maintained when operating in this up-scalable foam-based immobilized configuration in comparison to the slurry mode, using the same amount of $\mathrm{H}_{2} \mathrm{O}_{2}$, what is very encouraging for improving the 
viability of the photoassisted process. Obviously, it must be said that $0.564 \mathrm{~g}$ and $0.552 \mathrm{~g}$ of SG-LFO and P25-LFO active phase were respectively used on the $\beta$-SiC foams, compared to $0.05 \mathrm{~g}$ in the case of the powder suspensions that operate in optimal conditions at a $0.5 \mathrm{~g} / \mathrm{L}$ concentration, so that $4.4 \%$ and $3.8 \%$ of the intrinsic activity of the catalysts is preserved upon immobilization (averaged over the entire volume of the foam/reactor).

\subsubsection{Influence of the irradiance on the activity of the SG-LFO/ß-SiC foam in the combined process}

Taking into account the light transmission profile across the alveolar $\beta$-SiC foam (Figure 1B), the number of photons received by the catalyst is lower as we move towards the core of the foam volume ${ }^{11}$. Consequently, while the external surface of the foam catalyst operates in optimum lighting conditions with an incident irradiance of $60 \mathrm{~W} \mathrm{~m}^{-2}$, the catalyst clearly deviates from those conditions as it localizes closer to the foam core, and gradually operates via a dark-CWPO process. Figure 8 shows the influence of the incident UV-A irradiance, within the $60-240 \mathrm{~W} \mathrm{~m}^{-2}$ range, on the evolution with time of the main reaction parameters, as well as on the different apparent kinetic rate constants for the combined photo-CWPO and photocatalytic degradation of 4-CP over the SG$\mathrm{LFO} / \beta-\mathrm{SiC}$ foam catalyst. Increasing the irradiance from $60 \mathrm{Wm}^{-2}$ to $90-120 \mathrm{Wm}^{-2}$ strongly increases the different apparent kinetic rate constants till reaching a plateau for higher irradiances, with a consequent reduction of the time needed to achieve full 4-CP and TOC conversion, down to $75 \mathrm{~min}$ and $90 \mathrm{~min}$, respectively. This correlates with the maximum rate of $\mathrm{H}_{2} \mathrm{O}_{2}$ decomposition obtained for irradiances higher than $120 \mathrm{Wm}^{-2}$. 

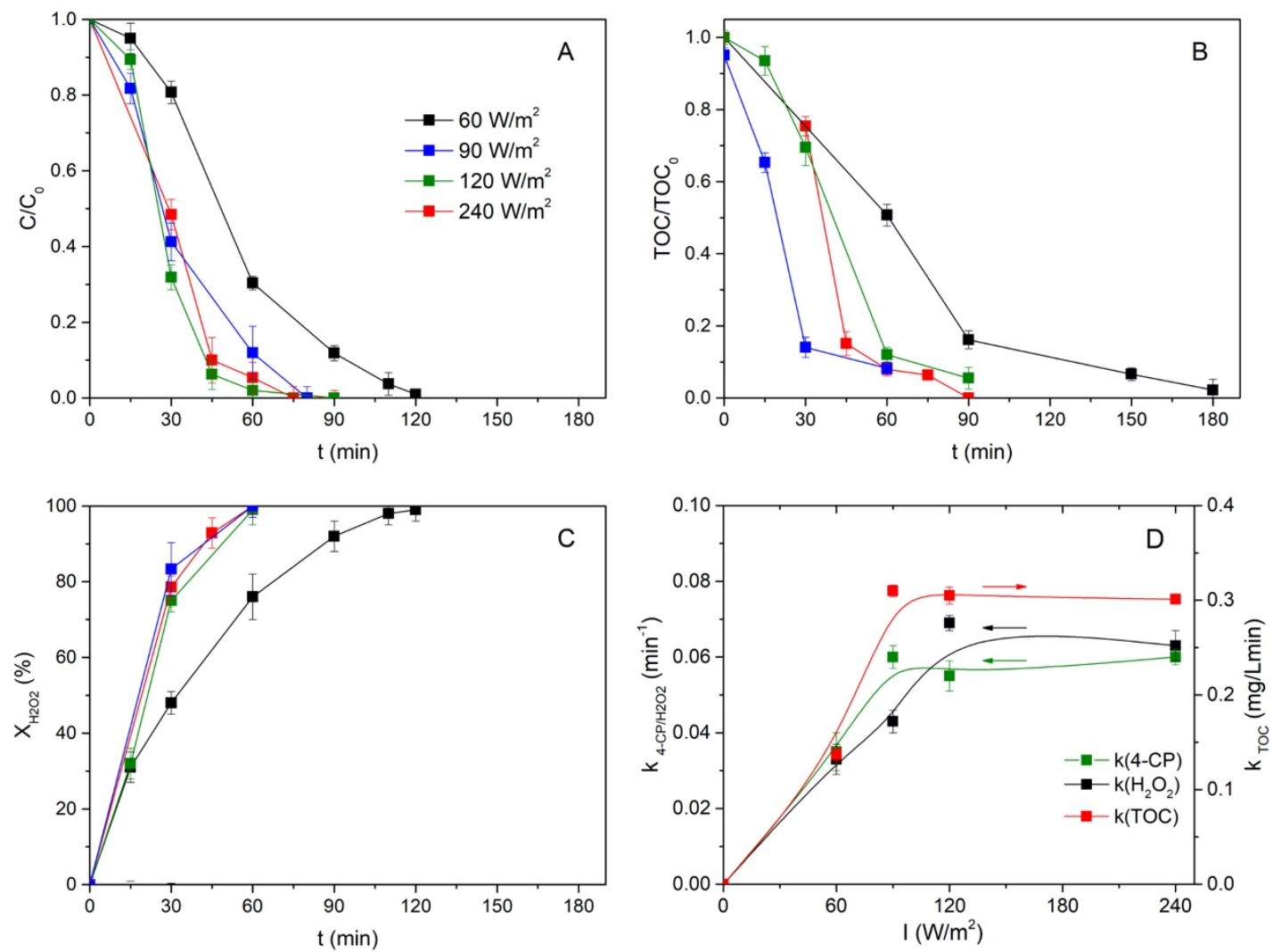

Figure 8: Influence of the UV-A irradiance on the evolution with time under irradiation of $(\mathbf{A})$ the relative 4-CP concentration, $(\mathbf{B})$ the relative TOC concentration and $(\mathbf{C})$ the $\mathrm{H}_{2} \mathrm{O}_{2}$ decomposition yield during the combined photo-CWPO and photocatalytic degradation of 4-CP over the SG-LFO/ $\beta$-SiC foam catalyst. (D) Influence of the UV-A irradiance on the apparent kinetic rate constants of 4-CP degradation, TOC conversion and $\mathrm{H}_{2} \mathrm{O}_{2}$ decomposition. Conditions: $[4-\mathrm{CP}]_{0}=25 \mathrm{mg} / \mathrm{L} ;\left[\mathrm{H}_{2} \mathrm{O}_{2}\right]_{0}=125 \mathrm{mg} / \mathrm{L} ; \mathrm{T}=25^{\circ} \mathrm{C}$; UV-A irradiance of $60-240 \mathrm{~W} \mathrm{~m}^{-2}$.

The profile with increasing irradiance is suggested to result from the direct influence of the irradiance on the $\mathrm{H}_{2} \mathrm{O}_{2}$ decomposition rate, that was reported by Carra et al. to be irradiance-limited at low irradiance and iron-limited at higher irradiance ${ }^{64}$. In their study, the authors observed UV-light saturation within the 5-15 $\mathrm{Wm}^{-2}$ range depending on the 
light path length $(5-10 \mathrm{~cm})$, while several works report that increasing the UV light irradiance linearly increase both the $\mathrm{H}_{2} \mathrm{O}_{2}$ and the pollutant decomposition rates when a photo-Fenton catalyst operates in irradiance-limited conditions ${ }^{65,66}$. In consequence, here the catalyst performance benefits from the possibility to increase the kinetic rate constants in the under-irradiated core areas of the foam catalyst, which are considered to operate in irradiance-limited conditions, while the reaction rates are iron-limited on the external surface of the foam independently of the irradiance level.

\subsubsection{Stability and reusability of the SG-LFO/ß-SiC foam catalyst}

The stability and reusability of catalysts are necessary key-properties for water treatment, so that reusability tests with sequential runs were performed with the most active SG-LFO/ $\beta-\mathrm{SiC}$ foam catalyst. Fig. 9 and Table 2 demonstrate the ability of the foam catalyst to be reused, complete 4-CP elimination being achieved after 120 min over at least 4 reaction cycles with no significant change in the pseudo kinetic rate constants, at $0.036 \pm 0.001 \mathrm{~min}^{-1}$. Similar initial 4-CP mineralization rates of $0.138 \pm 0.004 \mathrm{~min}^{-1}$ are also maintained, while the mineralization rate assigned to pure UV-A photocatalysis at the end of the test is also not altered, at $0.023 \pm 0.001 \mathrm{mgL}^{-1} \mathrm{~min}^{-1}$. Only a slight decrease in the mineralization degree obtained after $180 \mathrm{~min}$ of reaction is observed from $100 \%$ to $96.5 \%$ after the $4^{\text {th }}$ cycle. What is more, the leached iron to the solution was followed during the time-course of the reaction, and remained below the detection threshold (i.e. lower than $0.00008 \%$ relative to the catalyst Fe content). This demonstrates the robustness of the immobilized $\mathrm{SG}-\mathrm{LFO} / \beta-\mathrm{SiC}$ foam catalyst, that can be reused in a plug-and-play mode while continuously operating through pure heterogeneous surface reactions without any homogeneous contribution. 

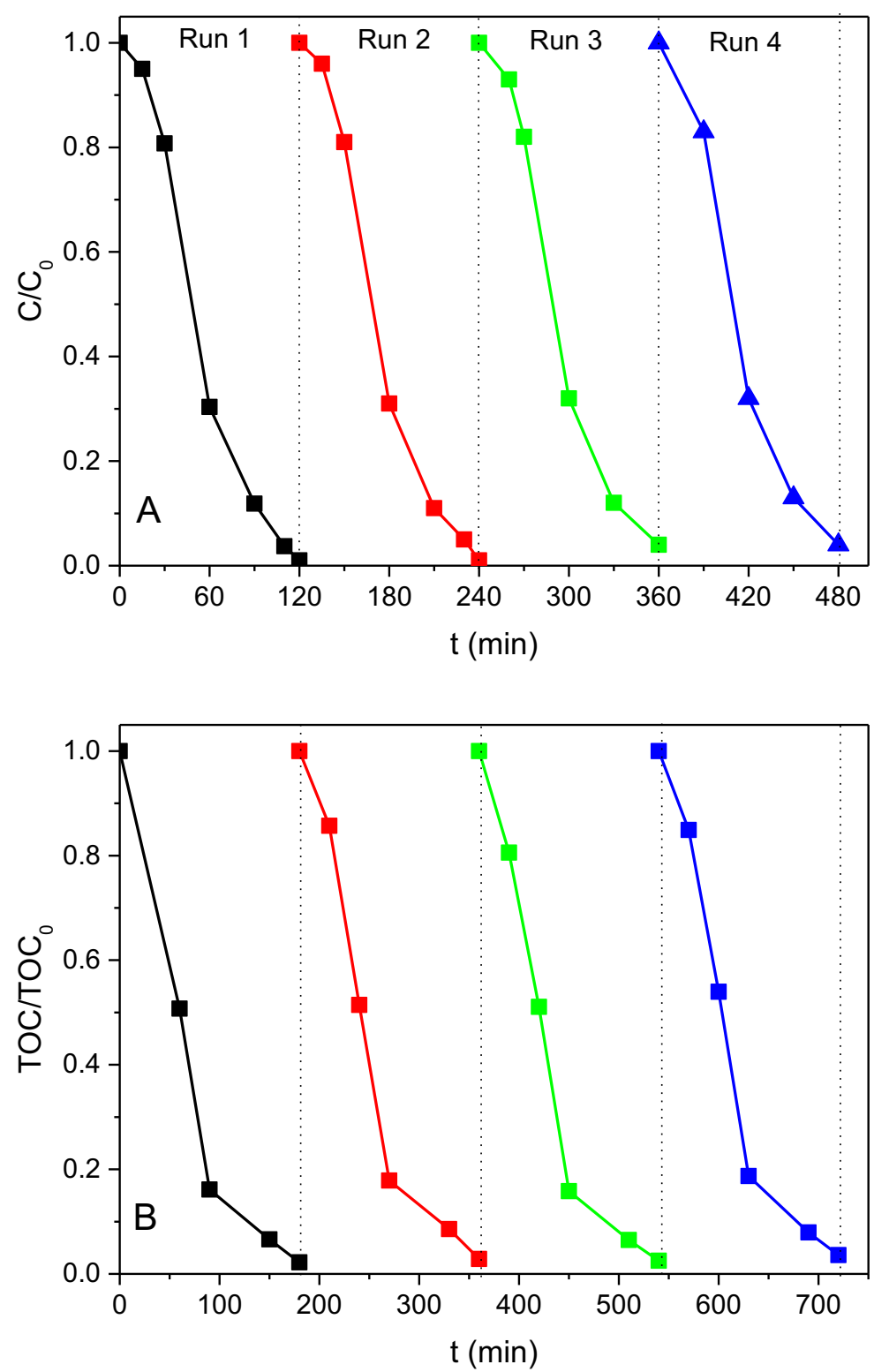

Figure 9: Catalyst recycling efficiency expressed in terms of time-evolution of both (A) the $\mathrm{C} / \mathrm{C}_{0}$ and $(\mathrm{B})$ the $\mathrm{TOC} / \mathrm{TOC}_{0}$ for 4 consecutive runs in the combined photo-Fenton and photocatalytic degradation of $4-\mathrm{CP}$ with the $\mathrm{SG}-\mathrm{LFO} / \beta-\mathrm{SiC}$ foam catalyst. Conditions: $[4-\mathrm{CP}]_{0}=25 \mathrm{mg} / \mathrm{L} ;\left[\mathrm{H}_{2} \mathrm{O}_{2}\right]_{0}=125 \mathrm{mg} / \mathrm{L} ; \mathrm{T}=25^{\circ} \mathrm{C}$; UV-A irradiance of $60 \mathrm{~W}$ $\mathrm{m}^{-2}$. No washing or thermal treatment was applied to the SG-LFO/ $/$-SiC foam catalyst after each run. 


\section{CONCLUSION}

We report here on the use of Ti-modified $\mathrm{LaFeO}_{3} / \beta-\mathrm{SiC}$ alveolar structured foams as immobilized, highly robust dual catalyst with combined photocatalytic and $\mathrm{H}_{2} \mathrm{O}_{2}$ mediated photo-CWPO activity under UV-A light that overcomes the drawback of working with powdery catalysts in water treatment. Taking the removal of 4-CP as test reaction, we demonstrate that this macroscopic $\beta$-SiC foam supported Ti-modified $\mathrm{LaFeO}_{3}$ dual catalyst, optimized with 10 wt.\% active phase content, combines the advantages of both AOPs for achieving high mineralization rates and complete TOC conversions under UV-A light at circumneutral $\mathrm{pH}$ conditions, without any Fe release to the solution. The immobilized catalyst with dual photo-CWPO/photocatalytic activity leads to photonic efficiencies for 4-CP degradation and mineralization of ca. $9.4 \%$ and $38 \%$, respectively, which strongly outperform those obtained with a reference $\beta$-SiC foam supported $\mathrm{TiO}_{2} \mathrm{P} 25$ photocatalyst. In agreement with the catalytic behaviour, we propose that titanium atoms inside the immobilized $\mathrm{LaFeO}_{3}$ unit cell form a substituted $\mathrm{La}_{1}$ ${ }_{x} \mathrm{Ti}_{\mathrm{x}} \mathrm{FeO}_{3}$ catalyst analogous to its powdery counterpart. The Ti modification of the supported ferrite enables a strong enhancement of the catalyst robustness by more than three orders of magnitude, as evidenced by the inhibition of Fe leaching to the solution, that allows the alveolar foam-based dual catalyst to operate via pure heterogeneous surface reactions. In consequence, the immobilized catalyst can be used over several test cycles without any reduction in the apparent kinetic rate constants. This is a prior step before scaling to a pilot plant scale prototype to assess the activity and stability of our $\mathrm{La}_{1-\mathrm{x}} \mathrm{Ti}_{\mathrm{x}} \mathrm{FeO}_{3} / \beta-\mathrm{SiC}$ catalysts closer to real implementation.

\section{ASSOCIATED CONTENT}


Supporting Information SI1

Table S1: Concentrations of the precursors in the aqueous impregnation solution or suspension used for the incipient wetness impregnation of the $\beta$-SiC foams. Synthesis of the amorphous titania precursor.

Supporting Information SI2: Advanced X-ray diffraction (XRD) recording

Supporting Information SI3: Photonic efficiencies

Figure S1: Discretization of the foam surface into cylinders of increasing radius from the centre and irradiance received by each of these cylinders from a lamp placed at 10 $\mathrm{cm}$ from the external border of the foam.

Figure S2: (A) $\mathrm{N}_{2}$ adsorption-desorption isotherms and (B) pore size distribution of the bare $\beta$-SiC foam support, of the reference $\mathrm{LFO} / \beta-\mathrm{SiC}$ foam and of both $\mathrm{P} 25-\mathrm{LFO} / \beta$ $\mathrm{SiC}$ and $\mathrm{SG}-\mathrm{LFO} / \beta-\mathrm{SiC}$ foam catalysts.

Figure S3: Observed (black), calculated (orange full line), and difference (black full line) XRD patterns of the $\mathrm{SG}-\mathrm{LFO} / \beta-\mathrm{SiC}$ foam catalyst recorded on a Brucker D8 Discover diffractometer $(\lambda=1.54056 \AA)$, equipped with a LynxEye XE-T detector, a motorized anti-scatter screen and a $\mathrm{Si}$ low background sample holder for minimizing at the maximum the background noise.

Figure S4: (A) Simulated normalized intensity $\mathrm{I}_{\mathrm{hkl}}(\mathrm{LFO}) / \mathrm{I}_{112}(\mathrm{LFO})$ and (B) its relative variation as a function of the $\mathrm{Ti} \rightarrow \mathrm{La}$ substitution ratio within the LFO structure for selected characteristic Bragg peaks, namely (110), (111), (220) and (202). They characterize the detectability and the sensitivity of the (hkl) peak to the insertion of Ti into the LFO structure, respectively. (C) Simulated normalized intensity $\mathrm{I}_{110}(\mathrm{LFO}) / \mathrm{I}_{111}(\mathrm{SiC})$ of the (110) peak of LFO for a sample consisting in a $\mathrm{SiC}$ matrix with $12 \%$ of LFO, the (111) peak being the most intense in the case of fcc $\beta$-SiC. 
Figure S5: XPS profiles recorded on both the SG-LFO/ $\beta$-SiC foam and the SG-LFO catalysts, (A) wide scan survey spectrum, (B) La 3d, (C) Fe 2p and (D) Ti 2p orbitals. Figure S6: Time-evolution of both the $\mathrm{C} / \mathrm{C}_{0}$ and $\mathrm{TOC} / \mathrm{TOC}_{0}$ relative concentrations during the pure photocatalytic degradation of $4-\mathrm{CP}$ over the $\mathrm{P} 25 / \beta-\mathrm{SiC}$ foam. Immobilization protocol for the $\mathrm{P} 25 / \beta-\mathrm{SiC}$ foam

Figure S7: Evolution with time under irradiation of (a) the relative 4-CP concentration, (b) the relative TOC concentration and (c) the concentration of leached $\mathrm{Fe}$ in the solution during the combined photo-Fenton and photocatalytic degradation of 4-CP over the pristine LFO and both Ti-substituted P25-LFO and SG-LFO catalysts as powders.

Table S2: Apparent kinetic rate constants

Synthesis protocols for pristine LFO and both Ti-substituted P25-LFO and SG-LFO catalysts as powders

\section{AUTHOR INFORMATION}

\section{Corresponding Authors}

* patricia.gmunoz@upm.es ; nkeller@unistra.fr

\section{Author Contributions}

The manuscript was written through contributions of all authors. All authors have given approval to the final version of the manuscript. Patricia García-Muñoz performed all experimental work.

\section{Funding Sources}

Funding from European Fund Interreg V program.

\section{ACKNOWLEDGMENT}


The European Fund for regional development (EFRE/FEDER) is thanked for funding the project PHOTOPUR which is performed in the frame of the Interreg V program and the Offensive Sciences call. T. Dintzer (ICPEES) is thanked for performing SEM characterization.

The following graphic will be used for the TOC (images are original and were created by the authors of the article

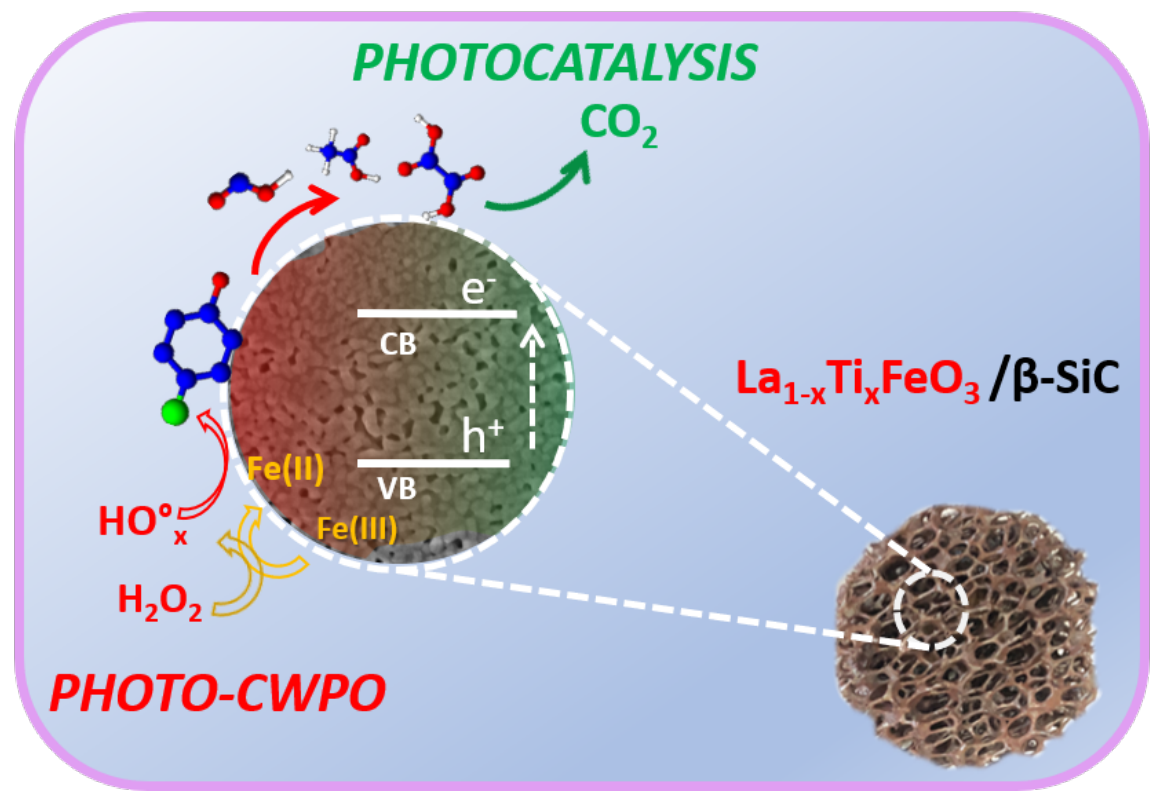

References

1. Malato, S.; Fernández-Ibáñez, P.; Maldonado, M. I.; Blanco, J.; Gernjak, W. Decontamination and Disinfection of Water by Solar Photocatalysis: Recent Overview and Trends. Catalysis Today 2009, 147, 1-59.

2. Coronado, J. M.; Fresno, F.; Hernández-Alonso, M. D.; Portela, R. Design of Advanced Photocatalytic Materials for Energy and Environmental Applications. Green Energy and Technology 2013, 71.

3. García-Muñoz, P.; Pliego, G.; Zazo, J. A.; Bahamonde, A.; Casas, J. A. Sulfonamides Photoassisted Oxidation Treatments Catalyzed by Ilmenite. Chemosphere 2017, 180, 523530 .

4. García-Muñoz, P.; Pliego, G.; Zazo, J. A.; Barbero, B.; Bahamonde, A.; Casas, J. A. Modified Ilmenite as Catalyst for CWPO-Photoassisted Process under LED Light. Chem. Eng. J. 2017, 318, 89-94. 
5. Mechakra, H.; Sehili, T.; Kribeche, M. A.; Ayachi, A. A.; Rossignol, S.; George, C. Use of Natural Iron Oxide as Heterogeneous Catalyst in Photo-Fenton-like Oxidation of Chlorophenylurea Herbicide in Aqueous Solution: Reaction Monitoring and Degradation Pathways. J. Photochem. Photobiol. A-Chem. 2016, 317, 140-150.

6. Cai, C.; Zhang, Z.; Liu, J.; Shan, N.; Zhang, H.; Dionysiou, D. D. Visible Light-assisted Heterogeneous Fenton with $\mathrm{ZnFe}_{2} \mathrm{O}_{4}$ for the Degradation of Orange II in Water. Applied Catalysis B: Environmental 2016, 182, 456-468.

7. Soltani, T.; Lee, B. Improving Heterogeneous Photo-Fenton Catalytic Degradation of Toluene under Visible Light Irradiation through Ba-doping in $\mathrm{BiFeO}_{3}$ Nanoparticles. $J$. Mol. Catal. A-Chem. 2016, 425, 199-207.

8. Garcia-Muñoz, P.; Fresno, F.; Lefevre, C.; Robert, D.; Keller, N. Highly Robust $\mathrm{La}_{1-\mathrm{x}} \mathrm{Ti}_{\mathrm{x}} \mathrm{FeO}_{3}$ Dual Catalyst with combined Photocatalytic and Photo-CWPO Activity under Visible Light for 4-chlorophenol Removal in Water. Applied Catalysis B: Environmental 2020, 262,118310 .

9. Garcia-Muñoz, P.; Lefevre, C.; Robert, D.; Keller, N. Ti-substituted $\mathrm{LaFeO}_{3}$ Perovskite as Photoassisted CWPO Catalyst for Water Treatment. Applied Catalysis B: Environmental 2019, 248, 120-128.

10. García-Muñoz, P.; Fresno, F.; Lefevre, C.; Robert, D.; Keller, N. Synergy Effect Between Photocatalysis and Heterogeneous PhotoFenton Catalysis on Ti-Doped $\mathrm{LaFeO}_{3}$ Perovskite for High Efficiency Light-Assisted Water Treatment. Catal. Sci. Technol. 2020, 10, 12991310 .

11. Masson, R.; Keller, V.; Keller, N. $\beta$-SiC Alveolar Foams as a structured Photocatalytic Support for the Gas Phase Photocatalytic Degradation of Methylethylketone. Applied Catalysis B: Environmental 2015, 170-171, 301-311.

12. Zhu, S.; Yang, X.; Yang, W.; Zhang, L.; Wang, J.; Huo, M. Application of Porous NickelCoated $\mathrm{TiO}_{2}$ for the Photocatalytic Degradation of Aqueous Quinoline in an Internal Airlift Loop Reactor. International Journal of Environmental Research and Public Health 2012, 9.

13. Ishiguro, H.; Yao, Y.; Nakano, R.; Hara, M.; Sunada, K.; Hashimoto, K.; Kajioka, J.; Fujishima, A.; Kubota, Y. Photocatalytic Activity of $\mathrm{Cu}^{2+} / \mathrm{TiO}_{2}$-coated Cordierite Foam inactivates Bacteriophages and Legionella Pneumophila. Applied Catalysis B: Environmental 2013, 129, 56-61.

14. Martín-Sómer, M.; Pablos, C.; de Diego, A.; van Grieken, R.; Encinas, Á; Monsalvo, V. M.; Marugán, J. Novel Macroporous 3D Photocatalytic Foams for simultaneous Wastewater Disinfection and Removal of Contaminants of Emerging Concern. Chemical Engineering Journal 2019, 366, 449-459.

15. Robert, D.; Keller, V.; Keller, N. Immobilization of a Semiconductor Photocatalyst on Solid Supports: Methods, Materials, and Applications, In Photocatalysis and Water Purification: From Fundamentals to Recent Applications, Pichat, P., Ed., Wiley-VCH Verlag GmbH \& Co. KGaA, 2013; Chapter 5, pp 145-178.

16. Švagelj, Z.; Mandić, V.; Ćurković, L.; Biošić, M.; Žmak, I.; and Gaborardi, M. TitaniaCoated Alumina Foam Photocatalyst for Memantine Degradation Derived by Replica Method and Sol-Gel Reaction. Materials (Basel, Switzerland) 2020, 13, 227. 
17. Kouamé, N. A.; Robert, D.; Keller, V.; Keller, N.; Pham, C.; Nguyen, P. Preliminary Study of the Use of $\beta-\mathrm{SiC}$ foam as a Photocatalytic Support for Water Treatment. Catalysis Today 2011, 161, 3-7.

18. Kouamé, A. N.; Masson, R.; Robert, D.; Keller, N.; Keller, V. $\beta$-SiC Foams as a Promising Structured Photocatalytic Support for Water and Air Detoxification. Catalysis Today 2013, 209, 13-20.

19. M'Bra, I. C.; García-Muñoz, P.; Drogui, P.; Keller, N.; Trokourey, A.; Robert, D. Heterogeneous Photodegradation of Pyrimethanil and its commercial Formulation with $\mathrm{TiO}_{2}$ immobilized on SiC Foams. J. Photochem. Photobiol. A Chem. 2019, 368, 1-6.

20. Allé, P. H.; Garcia-Muñoz, P.; Adouby, K.; Keller, N.; Robert, D. Efficient Photocatalytic Mineralization of Polymethylmethacrylate and Polystyrene Nanoplastics by $\mathrm{TiO}_{2} / \beta-\mathrm{SiC}$ Alveolar Foams. Environmental Chemistry Letters 2020. https://doi.org/10.1007/s10311020-01099-2.

21. Rico-Santacruz, M.; García-Muñoz, P.; Keller, V.; Batail, N.; Pham, C.; Robert, D.; Keller, N. Alveolar $\mathrm{TiO}_{2}-\beta-\mathrm{SiC}$ Photocatalytic Composite foams with tunable Properties for Water Treatment. Catalysis Today 2019, 328, 235-242.

22. Rico-Santacruz, M.; García-Muñoz, P.; Marchal, C.; Batail, N.; Pham, C.; Robert, D.; Keller, N. Coating-free $\mathrm{TiO}_{2} @ \beta$-SiC Alveolar Foams as a Ready-to-use Composite Photocatalyst with tunable Adsorption Properties for Water Treatment. RSC Adv. 2020, 10, 3817-3825.

23. Plantard, G.; Goetz, V.; Sacco, D. $\mathrm{TiO}_{2}$-coated Foams as a Medium for Solar Catalysis. Materials Research Bulletin 2011, 46, 231-234.

24. Do, T. M.; Byun, J. Y.; Kim, S. H. Magnetite-coated Metal Foams as one-body Catalysts for Fenton-like Reactions. Research on Chemical Intermediates 2017, 43, 3481-3492.

25. Li, S.; Zhang, G.; Zheng, H.; Zheng, Y.; Wang, P. Application of $\mathrm{BiFeO}_{3}$-based onNnickel Foam Composites with a Highly Efficient Catalytic Activity and easily Recyclable in Fenton-like Process under Microwave Irradiation. Journal of Power Sources 2018, 386, 21-27.

26. Yang, J.; Zhang, Q.; Zhang, F.; Xia, D.; Liu, H.; Tian, S.; Sun, L.; Shu, D.; He, C.; Runa, S. Three-dimensional Hierarchical Porous Sludge-derived Carbon supported on Silicon Carbide Foams as effective and stable Fenton-like Catalyst for odorous Methyl mercaptan elimination. Journal of Hazardous Materials 2018, 358, 136-144.

27. Ou, X.; Pilitsis, F.; Xu, N.; Taylor, S. F. R.; Warren, J.; Garforth, A.; Zhang, J.; Hardacre, C.; Jiao, Y.; Fan, X. On developing Ferrisilicate Catalysts supported on Silicon Carbide ( $\mathrm{SiC})$ Foam Catalysts for continuous Catalytic Wet Peroxide Oxidation (CWPO) Reactions. Catalysis Today 2018, 362, 53-62.

28. Ou, X.; Pilitsis, F.; Jiao, Y.; Zhang, Y.; Xu, S.; Jennings, M.; Yang, Y.; Taylor, S. F. R.; Garforth, A.; Zhang, H.; Hardacre, C.; Yan, Y.; Fan, X. Hierarchical Fe-ZSM-5/SiC Foam Catalyst as the Foam Bed Catalytic Reactor (FBCR) for Catalytic Wet Peroxide Oxidation (CWPO). Chemical Engineering Journal 2019, 362, 53-62. 
29. Orak, C.; Atalay, S.; Ersöz, G. Photocatalytic and Photo-Fenton-like Degradation of Methylparaben on Monolith-supported Perovskite-type Catalysts. Sep. Sci. Technol. 2017, $52,1310-1320$.

30. Abdi, P.; Farzi, A.; Karimi, A. Application of a Hybrid Enzymatic and Photo-Fenton Process for investigation of Azo Dye Decolorization on $\mathrm{TiO}_{2} /$ metal-foam Catalyst. Journal of the Taiwan Institute of Chemical Engineers 2017, 71, 137-144.

31. Munoz, M.; de Pedro, Z. M.; Casas, J. A.; Rodriguez, J. J. Combining efficiently Catalytic Hydrodechlorination and Wet Peroxide Oxidation (HDC-CWPO) for the Abatement of Organochlorinated Water Pollutants. Applied Catalysis B: Environmental 2014, 150-151, 197-203.

32. Nguyen, P.; Pham, C. Innovative porous SiC-based materials: From Nanoscopic understandings to Tunable Carriers serving Catalytic Needs. Applied Catalysis A: General 2011, 391, 443-454.

33. Edouard, D.; Lacroix, M.; Pham, C.; Mbodji, M.; Pham-Huu, C. Experimental Measurements and Multiphase Flow Models in Solid SiC Foam Beds. AIChE J. 2008, 54, 2823-2832.

34. Huu, T. T.; Lacroix, M.; Pham Huu, C.; Schweich, D.; Edouard, D. Towards a more Realistic Modeling of Solid Foam: Use of the Pentagonal Dodecahedron Geometry. Chemical Engineering Science 2009, 64, 5131-5142.

35. Lacroix, M.; Nguyen, P.; Schweich, D.; Pham Huu, C.; Savin-Poncet, S.; Edouard, D. Pressure Drop Measurements and Modeling on SiC foams. Chemical Engineering Science 2007, 62, 3259-3267.

36. Ledoux, M. J.; Pham-Huu, C. Silicon Carbide: A Novel Catalyst Support for Heterogeneous Catalysis. CATTECH 2001, 5, 226-246.

37. Gosavi, P. V.; Biniwale, R. B. Pure Phase $\mathrm{LaFeO}_{3}$ Perovskite with improved Surface Area Synthesized using Different Routes and its Characterization. Mater. Chem. Phys. 2010, 119, 324-329.

38. Pera-Titus, M.; García-Molina, V.; Baños, M. A.; Giménez, J.; Esplugas, S. Degradation of Chlorophenols by means of Advanced Oxidation Processes: a General Review. Applied Catalysis B: Environmental 2004, 47, 219-256.

39. Eisenberg, G. Colorimetric Determination of Hydrogen Peroxide; Industrial \& Engineering Chemistry Analytical: 1943, 15(5), 327-328.

40. Sandell, E. B. Colorimetric Determination of Traces of Metals. The Journal of Physical Chemistry: 1945; 49, 263-264.

41. Keller, N.; Di Grégorio, F.; Pham-Huu, C.; Keller, V. Towards the Oxygenated Phase Coverage Rate of $\beta$-SiC Surface. Diamond and Related Materials 2008, 17, 1867-1870.

42. Keller, N.; Pham-Huu, C.; Roy, S.; Ledoux, M. J.; Estournes, C.; Guille, J. Influence of the Preparation Conditions on the Synthesis of High Surface Area SiC for Use as a Heterogeneous Catalyst Support. J. Mater. Sci. 1999, 34, 3189-3202. 
43. Keller, N.; Pham-Huu, C.; Estournès, C.; Ledoux, M. J. Low Temperature use of SiCsupported $\mathrm{NiS}_{2}$-based Catalysts for Selective $\mathrm{H}_{2} \mathrm{~S}$ Oxidation: Role of $\mathrm{SiC}$ surface Heterogeneity and Nature of the Active Phase. Applied Catalysis A: General 2002, 234, 191-205.

44. Rebmann, G.; Keller, V.; Ledoux, M. J.; Keller, N. Cu-Y Zeolite Supported on Silicon Carbide for the Vapour Phase Oxidative Carbonylation of Methanol to Dimethyl Carbonate. Green Chem. 2008, 10, 207-213.

45. Winé, G.; Tessonnier, J.; Rigolet, S.; Marichal, C.; Ledoux, M.; Pham-Huu, C. Beta Zeolite supported on a $\beta$-SiC Foam Monolith: A diffusionless Catalyst for Fixed-bed FriedelCrafts Reactions. Journal of Molecular Catalysis A: Chemical 2006, 248, 113-120.

46. Ivanova, S.; Louis, B.; Madani, B.; Tessonnier, J. P.; Ledoux, M. J.; Pham-Huu, C. ZSM-5 Coatings on SiC Monoliths: Possible New Structured Catalyst for the Methanol-to-Olefins Process. J. Phys. Chem. C 2007, 111, 4368-4374.

47. Groppi, G.; Tronconi, E. Design of Novel Monolith Catalyst Supports for Gas/solid Reactions with Heat Exchange. Chemical Engineering Science 2000, 55, 2161-2171.

48. Shen, Z.; Chen, J.; Li, B.; Li, G.; Li, J.; Hou, X. A Novel Two-stage Synthesis for 3C-SiC Nanowires by Carbothermic Reduction and their Photoluminescence Properties. J. Mater. Sci. 2019, 54, 12450-12462.

49. Thirumalairajan, S.; Girija, K.; Ganesh, V.; Mangalaraj, D.; Viswanathan, C.; Ponpandian,

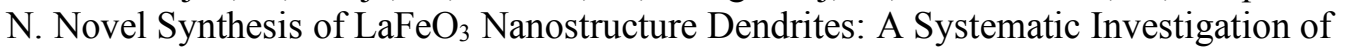
Growth Mechanism, Properties, and Biosensing for Highly Selective Determination of Neurotransmitter Compounds. Crystal Growth \& Design 2013, 13, 291-302.

50. Humayun, M.; Sun, N.; Raziq, F.; Zhang, X.; Yan, R.; Li, Z.; Qu, Y.; Jing, L. Synthesis of $\mathrm{ZnO} / \mathrm{Bi}$-doped porous $\mathrm{LaFeO}_{3}$ Nanocomposites as Highly Efficient Nano-Photocatalysts dependent on the Enhanced Utilization of Visible-light-excited Electrons. Applied Catalysis B: Environmental 2018, 231, 23-33.

51. Petrović, S.; Terlecki-Baričević, A.; Karanović, L.; Kirilov-Stefanov, P.; Zdujić, M.; Dondur, V.; Paneva, D.; Mitov, I.; Rakić, V. $\mathrm{LaMO}_{3}(\mathrm{M}=\mathrm{Mg}$, Ti, Fe) Perovskite Type Oxides: Preparation, Characterization and Catalytic Properties in Methane Deep Oxidation. Applied Catalysis B: Environmental 2008, 79, 186-198.

52. Faye, J.; Baylet, A.; Trentesaux, M.; Royer, S.; Dumeignil, F.; Duprez, D.; Valange, S.; Tatibouët, J. Influence of Lanthanum Stoichiometry in $\mathrm{La}_{1-\mathrm{x}} \mathrm{FeO}_{3-\delta}$ Perovskites on their Structure and Catalytic Performance in $\mathrm{CH}_{4}$ Total Oxidation. Applied Catalysis B: Environmental 2012, 126, 134-143.

53. Yamashita, T.; Hayes, P. Analysis of XPS spectra of $\mathrm{Fe}^{2+}$ and $\mathrm{Fe}^{3+}$ Ions in Oxide Materials. Appl. Surf. Sci. 2008, 254, 2441-2449.

54. Pliego, G.; Zazo, J. A.; Casas, J. A.; Rodriguez, J. J. Fate of Iron Oxalates in Aqueous Solution: The Role of Temperature, Iron Species and Dissolved Oxygen. Journal of Environmental Chemical Engineering 2014, 2, 2236-2241.

55. Zazo, J. A.; Pliego, G.; García-Muñoz, P.; Casas, J. A.; Rodriguez, J. J. UV-LED assisted Catalytic Wet Peroxide Oxidation with a Fe(II)-Fe(III)/activated Carbon Catalyst. Applied Catalysis B: Environmental 2016, 192, 350-356. 
56. Pliego, G.; Zazo, J. A.; Garcia-Muñoz, P.; Munoz, M.; Casas, J. A.; Rodriguez, J. J. Trends in the Intensification of the Fenton Process for Wastewater Treatment: An Overview. Crit. Rev. Environ. Sci. Technol. 2015, 45, 2611-2692.

57. García-Muñoz, P.; Zussblatt, N. P.; Pliego, G.; Zazo, J. A.; Fresno, F.; Chmelka, B. F.; Casas, J. A. Evaluation of Photoassisted Treatments for Norfloxacin Removal in water using Mesoporous $\mathrm{Fe}_{2} \mathrm{O}_{3}-\mathrm{TiO}_{2}$ Materials. Journal of Environmental Management 2019, $238,243-250$.

58. Kouamé, N. A.; Robert, D.; Keller, V.; Keller, N.; Pham, C.; Nguyen, P. TiO $2 / \beta-S i C$ Foamstructured Photoreactor for Continuous Wastewater Treatment. Environmental Science and Pollution Research 2012, 19, 3727-3734.

59. Ayodele, O. B.; Lim, J. K.; Hameed, B. H. Degradation of Phenol in Photo-Fenton Process by Phosphoric acid modified Kaolin supported Ferric-oxalate Catalyst: Optimization and kinetic Modeling. Chemical Engineering Journal 2012, 197, 181-192.

60. García-Muñoz, P.; Pliego, G.; Zazo, J. A.; Munoz, M.; De Pedro, Z. M.; Bahamonde, A.; Casas, J. A. Treatment of Hospital Wastewater through the CWPO-Photoassisted Process catalyzed by ilmenite. J. Environ. Chem. Eng. 2017, 5, 4337-4343.

61. De Laat, J.; Gallard, H. Catalytic Decomposition of Hydrogen Peroxide by Fe(III) in Homogeneous Aqueous Solution: Mechanism and Kinetic Modeling. Environ. Sci. Technol. 1999, 33, 2726-2732.

62. Lee, S.; Mills, A.; O'Rourke, C. The P25 $\mathrm{TiO}_{2} / 4-$ Chlorophenol Photocatalytic System: Spectral Sensitivity or Lamp Artefact? J. Photochem. Photobiol. A. 2017, 346, 153-158.

63. Theurich, J.; Lindner, M.; Bahnemann, D. W. Photocatalytic Degradation of 4-Chlorophenol in Aerated Aqueous Titanium Dioxide Suspensions: A Kinetic and Mechanistic Study. Langmuir 1996, 12, 6368-6376.

64. Carra, I.; García Sánchez, J. L.; Casas López, J. L.; Malato, S.; Sánchez Pérez, J. A. Phenomenological Study and Application of the combined Influence of Iron Concentration and Irradiance on the Photo-Fenton process to Remove Micropollutants. Science of The Total Environment 2014, 478, 123-132.

65. Lee, Y.; Jeong, J.; Lee, C.; Kim, S.; Yoon, J. Influence of various Reaction Parameters on 2,4-D Removal in Photo/ferrioxalate $/ \mathrm{H}_{2} \mathrm{O}_{2}$ Process. Chemosphere 2003, 51, 901-912.

66. Tokumura, M.; Ohta, A.; Znad, H. T.; Kawase, Y. UV Light assisted Decolorization of Dark Brown colored Coffee Effluent by Photo-Fenton Reaction. Water Research 2006, 40, 3775-3784. 


\section{Supporting Information}

\section{Ti-modified $\mathrm{LaFeO}_{3} / \beta$-SiC alveolar foams as immobilized dual catalyst with combined photo-Fenton and photocatalytic activity}

Patricia García-Muñoz, ${ }^{a}$ * Fernando Fresno, ${ }^{b}$ Christophe Lefevre, ${ }^{c}$ Didier Robert, ${ }^{a}$ Nicolas Keller ${ }^{a, *}$

${ }^{a}$ Institut de Chimie et Procédés pour l'Energie, l'Environnement et la Santé (ICPEES), CNRS/University of Strasbourg, 25 rue Becquerel, Strasbourg, France

b Photoactivated Processes Unit, IMDEA Energy, Móstoles, 28935, Madrid, Spain

' Institut de Physique et de Chimie des Matériaux de Strasbourg (IPCMS), CNRS/University de Strasbourg, 23 rue du Loess, Strasbourg, France corresponding authors* patricia.gmunoz@upm.es ; *nkeller@unistra.fr 


\section{Supporting Information SI1}

Table S1: Concentrations of the precursors in the aqueous impregnation solution or suspension used for the incipient wetness impregnation of the $\beta$-SiC foams. Synthesis of the amorphous titania precursor.

Supporting Information SI2: Advanced X-ray diffraction (XRD) recording

Supporting Information SI3: Photonic efficiencies

Supporting Information SI4: Synthesis protocols for pristine LFO and both Tisubstituted P25-LFO and SG-LFO catalysts as powders.

Figure S1: Discretization of the foam surface into cylinders of increasing radius from the centre and irradiance received by each of these cylinders from a lamp placed at 10 $\mathrm{cm}$ from the external border of the foam.

Figure S2: (A) $\mathrm{N}_{2}$ adsorption-desorption isotherms and (B) pore size distribution of the bare $\beta$-SiC foam support, of the reference $\mathrm{LFO} / \beta-\mathrm{SiC}$ foam and of both $\mathrm{P} 25-\mathrm{LFO} / \beta$ $\mathrm{SiC}$ and $\mathrm{SG}-\mathrm{LFO} / \beta-\mathrm{SiC}$ foam catalysts.

Figure S3: Observed (black), calculated (orange full line), and difference (black full line) XRD patterns of the $\mathrm{SG}-\mathrm{LFO} / \beta-\mathrm{SiC}$ foam catalyst recorded on a Brucker D8 Discover diffractometer $(\lambda=1.54056 \AA$ ), equipped with a LynxEye XE-T detector, a motorized anti-scatter screen and a $\mathrm{Si}$ low background sample holder for minimizing at the maximum the background noise. 
Figure S4: (A) Simulated normalized intensity $\mathrm{I}_{\mathrm{hkl}}(\mathrm{LFO}) / \mathrm{I}_{112}(\mathrm{LFO})$ and (B) its relative variation as a function of the $\mathrm{Ti} \rightarrow \mathrm{La}$ substitution ratio within the LFO structure for selected characteristic Bragg peaks, namely (110), (111), (220) and (202). They characterize the detectability and the sensitivity of the (hkl) peak to the insertion of Ti into the LFO structure, respectively. (C) Simulated normalized intensity $\mathrm{I}_{110}(\mathrm{LFO}) / \mathrm{I}_{112}(\mathrm{SiC})$ of the (110) peak of LFO for a sample consisting in a SiC matrix with $12 \%$ of LFO, the (111) peak being the most intense in the case of fcc $\beta$-SiC.

Figure S5: XPS profiles recorded on both the SG-LFO/ $\beta-\mathrm{SiC}$ foam and the SG-LFO catalysts, (A) wide scan survey spectrum, (B) La 3d, (C) Fe 2p and (D) Ti 2p orbitals.

Figure S6: Time-evolution of both the $\mathrm{C} \mathrm{C}_{0}$ and $\mathrm{TOC}^{\mathrm{TOC}} \mathrm{C}_{0}$ relative concentrations during the pure photocatalytic degradation of $4-\mathrm{CP}$ over the $\mathrm{P} 25 / \beta-\mathrm{SiC}$ foam. Immobilization protocol for the $\mathrm{P} 25 / \beta-\mathrm{SiC}$ foam

Figure S7: Evolution with time under irradiation of (a) the relative 4-CP concentration, (b) the relative TOC concentration and (c) the concentration of leached $\mathrm{Fe}$ in the solution during the combined photo-Fenton and photocatalytic degradation of 4-CP over the pristine LFO and both Ti-substituted P25-LFO and SG-LFO catalysts as powders.

Table S2: Apparent kinetic rate constants 


\section{Supporting Information SI1}

Table S1: Concentrations of the precursors in the aqueous impregnation solution or suspension used for the incipient wetness impregnation of the $\beta$-SiC foams $(15 \mathrm{~mL}$ of distilled water)

\begin{tabular}{lllll}
\hline Wt.\% of $\mathrm{LFO}$ & $\mathrm{La}\left(\mathrm{NO}_{3}\right)_{3} \times 6 \mathrm{H}_{2} \mathrm{O}$ & $\mathrm{Fe}\left(\mathrm{NO}_{3}\right)_{3} \times 9 \mathrm{H}_{2} \mathrm{O}$ & Citric acid & $\mathrm{TiO}_{2}$ \\
\hline 5 wt.\% & $54.2 \mathrm{~g} / \mathrm{L}$ & $66.5 \mathrm{~g} / \mathrm{L}$ & $35 \mathrm{~g} / \mathrm{L}$ & - \\
10 wt. $\%$ & $108.3 \mathrm{~g} / \mathrm{L}$ & $133 \mathrm{~g} / \mathrm{L}$ & $70 \mathrm{~g} / \mathrm{L}$ & $6.07 \mathrm{~g} / \mathrm{L}$ \\
20 wt. $\%$ & $216.6 \mathrm{~g} / \mathrm{L}$ & $266 \mathrm{~g} / \mathrm{L}$ & $140 \mathrm{~g} / \mathrm{L}$ & - \\
\hline
\end{tabular}

\section{Synthesis of the amorphous titania precursor:}

The amorphous titania material was synthesized according to a sol-gel method under basic conditions using TTIP as precursor. In a typical synthesis, $17.8 \mathrm{~g}$ of TTIP was first added to a $40 \mathrm{~mL}$ ethanolic solution at room temperature, before a similar volume of water was added dropwise to the solution. After rectification of the $\mathrm{pH}$ to 9 by adding ammonia (Carlo Erba, 30\% aqueous solution), the solution was left under agitation at room temperature until a dry paste was obtained. The resulting powder was further dried at $100^{\circ} \mathrm{C}$ for $12 \mathrm{~h}$. 


\section{Supporting Information SI2}

\section{Advanced X-ray diffraction (XRD) recording}

Advanced XRD recording was carried out on a Bruker D8 Discover diffractometer using a monochromatic copper radiation source with a scan step of $0.02^{\circ}$, and equipped with a LynxEye XE-T detector, a motorized anti-scatter screen and a Si low background sample holder for minimizing as much as possible the background noise. The Rietveld structural refinement of the $\mathrm{SG}-\mathrm{LFO} / \beta-\mathrm{SiC}$ foam pattern was performed with the Fullprof [1] software, using the modified Thompson-Cox-Hasting profile function (NPR $=7$ ) for generating the line shape of the diffraction peaks. Instrumental broadening was previously determined by measuring the scattering from corundum (NIST standard SRM 1976b) [1, 2]. Simulations on the theoretical variation of the peak intensities upon Ti substitution were performed for characterizing the detectability and the sensitivity to structural Ti of the main characteristic (hkl) Bragg peaks of the LFO phase. Given that the (112) peak at $2 \theta=32.2^{\circ}$ is the highest intensity peak among all the LFO (hkl) diffraction peaks, both parameters can be accessed by representing the normalized intensities $\left(\mathrm{I}_{\mathrm{hk}} / \mathrm{I}_{112}\right)$ and their relative variations as a function of the Ti amount inserted within the structure.

[1] Rodríguez-Carvajal, J. Recent Advances in Magnetic Structure Determination by Neutron Powder Diffraction, Physica B: Condensed Matter 1993, 192, 55-69.

[2] McCusker, L. B.; Von Dreele, R. B.; Cox, D. E.; Louër, D.; Scardi, P. Rietveld refinement guidelines, J. Appl. Cryst. 1999, 32, 36-50. 


\section{Supporting Information SI3}

\section{Photonic efficiencies}

In the first case, only the first electron (or hole) transfer was considered, so that the photonic efficiency was calculated as:

$$
\xi_{4-C P}(\%)=\frac{r_{4-C P}}{\Phi} \times 100
$$

where: $\quad \xi_{4-C P}:$ photonic efficiency for 4-CP oxidation $r_{4-C P}$ : reaction rate for 4-CP oxidation ([molecules] $\mathrm{s}^{-1}$ )

$\Phi:$ photon flux ([photons] $\left.\mathrm{s}^{-1}\right)$

Although the degradation of 4-CP follows a complex mechanism, [1] it can be assumed that every electron withdrawn in the oxidation path down to $\mathrm{CO}_{2}$ arises from an effectively utilized electron-hole pair upon photon absorption by the photocatalyst.[2] This can happen by direct reaction with a photo-hole, by mediation of a hydroxyl radical, or by reaction with a superoxide radical resulting from the extraction of a conduction band electron by oxygen. From a formal point of view, every 4-CP molecule converted to 6 molecules of $\mathrm{CO}_{2}$ has lost 26 electrons, which can therefore be translated into 26 effectively used photons. The photonic efficiency for mineralization, derived from TOC disappearance can thus be defined as:

$$
\xi_{\text {TOC }}(\%)=\frac{26 \times C_{i} \times V \times N_{A}}{\Phi \times t_{\text {miner }}} \times 100
$$

where: $\quad \xi_{T O C}:$ photonic efficiency for 4-CP mineralization

$C_{i}$ : initial 4-CP concentration $\left(\mathrm{mol} \mathrm{L}^{-1}\right)$

$V:$ reactor volume $(\mathrm{L})$

$N_{A}:$ Avogadro number $\left(\mathrm{mol}^{-1}\right)$ 
$t_{\text {miner }}$ : time for total mineralization, ie. to achieve $[\mathrm{TOC}]=0(\mathrm{~s})$

$$
\Phi: \text { photon flux }\left(\mathrm{s}^{-1}\right)
$$

For each of the two lamps used, assuming that the irradiance is constant along the lamp length, the photon flux $\Phi$ was calculated (i) from the irradiance measurements recorded at the external wall and the center of the reactor, considering that the irradiance decreases with the square of the distance from the light source, and (ii) taking into account that the foam support transmits light as determined experimentally in Figure 1 and expressed following a first order decreasing exponential model as a function of the foam radius $\mathrm{L}$ (Eq.S3).

$$
I=I_{0} \times e^{-L / 0.47}
$$

where $\mathrm{I}$ and $\mathrm{I}_{0}$ are the transmitted and incident light, respectively, and $\mathrm{L}$ is the radial distance in $\mathrm{cm}$ from the external surface of the foam (i.e. $L=0$ and $L=2.5$ corresponding to the external surface and the center of the foam, respectively).

Considering this, the foam is virtually discretized as the sum of 100 concentric cylinders of increasing radius, and the photon flux $\Phi$ is obtained by numerically integrating (Figure S1) the irradiance at the external surface of those cylinders, giving a value of $7.491 \times 10^{16}$ (photons) $\mathrm{s}^{-1}$. Theurich, J.; Lindner, M.; Bahnemann, D. W. Photocatalytic Degradation of 4-Chlorophenol in Aerated Aqueous Titanium Dioxide Suspensions: A Kinetic and Mechanistic Study, Langmuir 1996, 12, 6368-6376.

[2] Muñoz-Batista, M. J.; Kubacka, A.; Hungría, A. B.; Fernández-García, M. Heterogeneous Photocatalysis: Light-Matter Interaction and Chemical Efects in Quantum Efficiency Calculations. J. Catal. 2015, 330, 154-166. 


\section{Supporting Information SI4}

\section{Synthesis protocol}

Powdery $\mathrm{La}_{1-\mathrm{x}} \mathrm{Ti}_{\mathrm{x}} \mathrm{FeO}_{3}$ catalysts were obtained by modifying a sol-gel Pechini synthesis. The synthesis method has been described in Garcia-Munoz et al. [1] by using two titania with distinguished crystal size and properties as titanium precursors.

The reference titanium-free $\mathrm{LaFeO}_{3}$ catalyst was labelled as LFO, while the Ti-modified $\mathrm{LaFeO}_{3}$ catalysts were labelled as P25-LFO and SG-LFO when using AeroxideC $\mathrm{TiO}_{2}$ P25 and dried amorphous titania as titanium sources, respectively. Regardless of the titanium source, the titanium added during the Pechini synthesis corresponded to a nominal amount of $10 \mathrm{wt} \%$ in terms of $\mathrm{TiO}_{2}$ with respect to the theoretical amount of $\mathrm{LaFeO}_{3}$ orthoferrite obtained.

[1] García-Muñoz, P.; Fresno, F.; Lefevre, C.; Robert, D.; Keller, N. Synergy Effect Between Photocatalysis and Heterogeneous PhotoFenton Catalysis on Ti-Doped $\mathrm{LaFeO}_{3}$ Perovskite for High Efficiency Light-Assisted Water Treatment, Catal. Sci. Technol. 2020, 10, 1299-1310. 


\section{Figure S1}

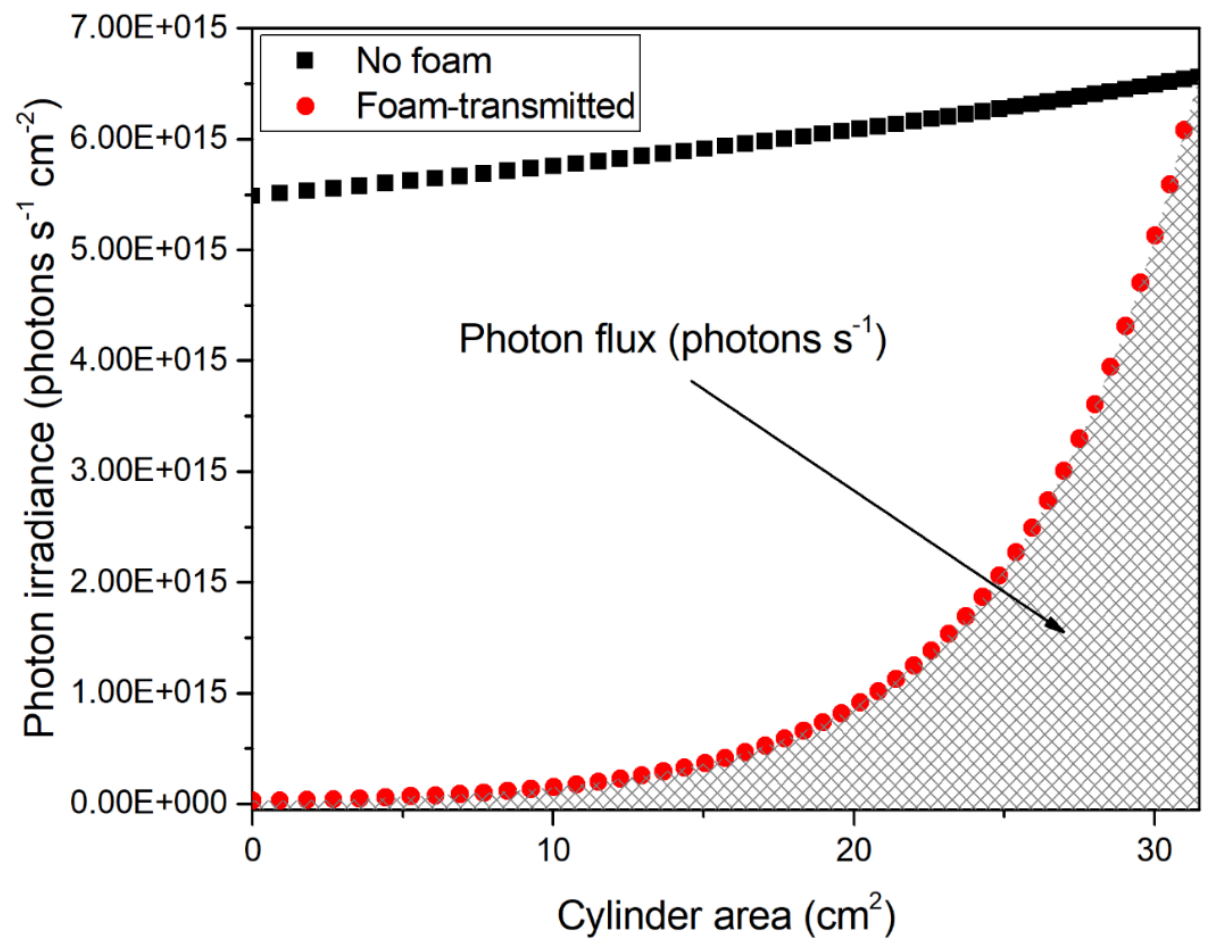

Figure S1. Discretization of the foam surface into cylinders of increasing radius from the centre and irradiance received by each of these cylinders from a lamp placed at $10 \mathrm{~cm}$ from the external border of the foam. The numerical integration of the irradiance curve (shaded area) gives the total amount of photons incident per unit time in the whole foam volume. 
Figure S2
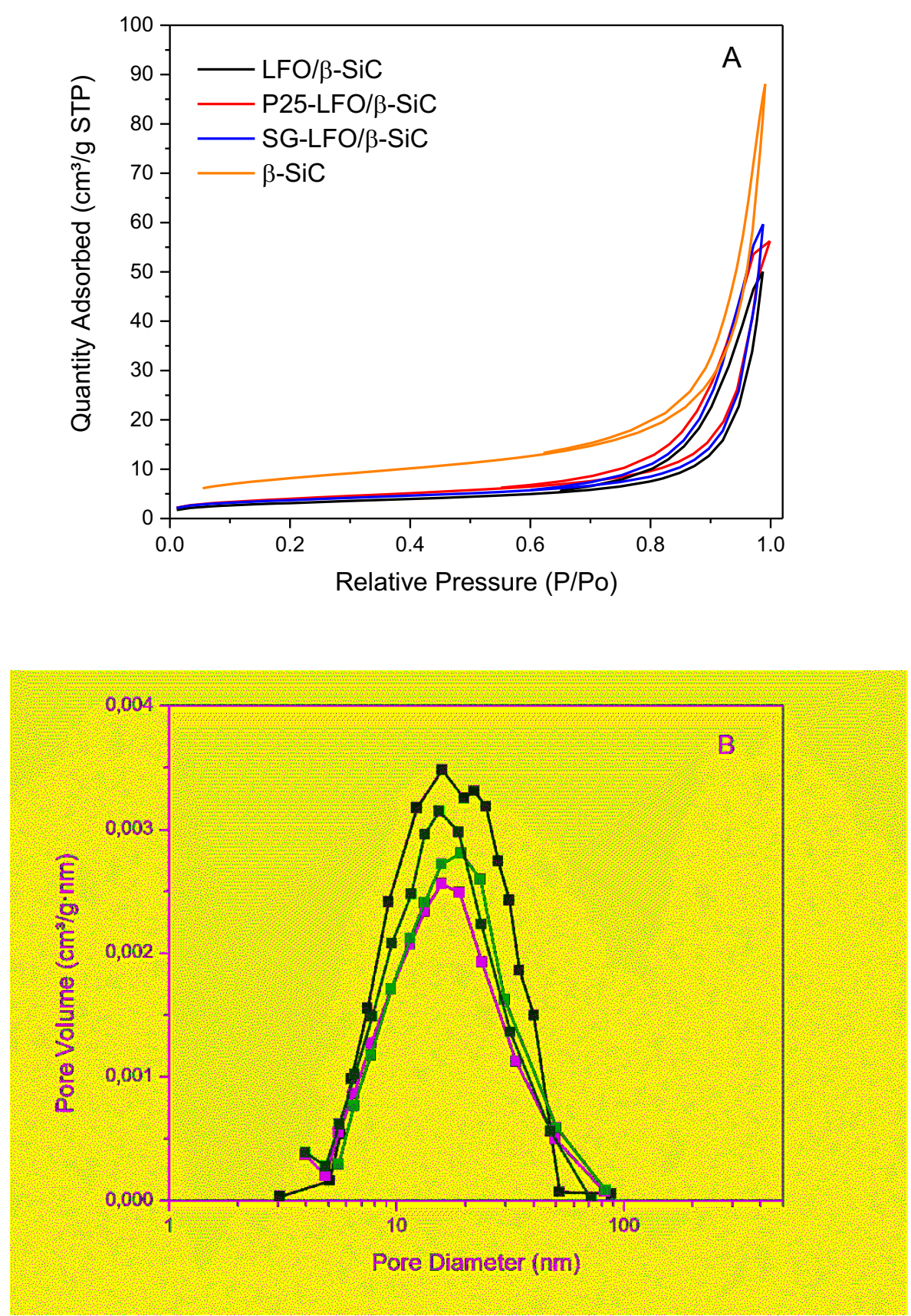

Figure S2. (A) $\mathrm{N}_{2}$ adsorption-desorption isotherms and (B) pore size distribution of the bare $\beta$-SiC foam support, of the reference $\mathrm{LFO} / \beta-\mathrm{SiC}$ foam and of both $\mathrm{P} 25-\mathrm{LFO} / \beta-\mathrm{SiC}$ and $\mathrm{SG}-\mathrm{LFO} / \beta-\mathrm{SiC}$ foam catalysts. 
Figure S3

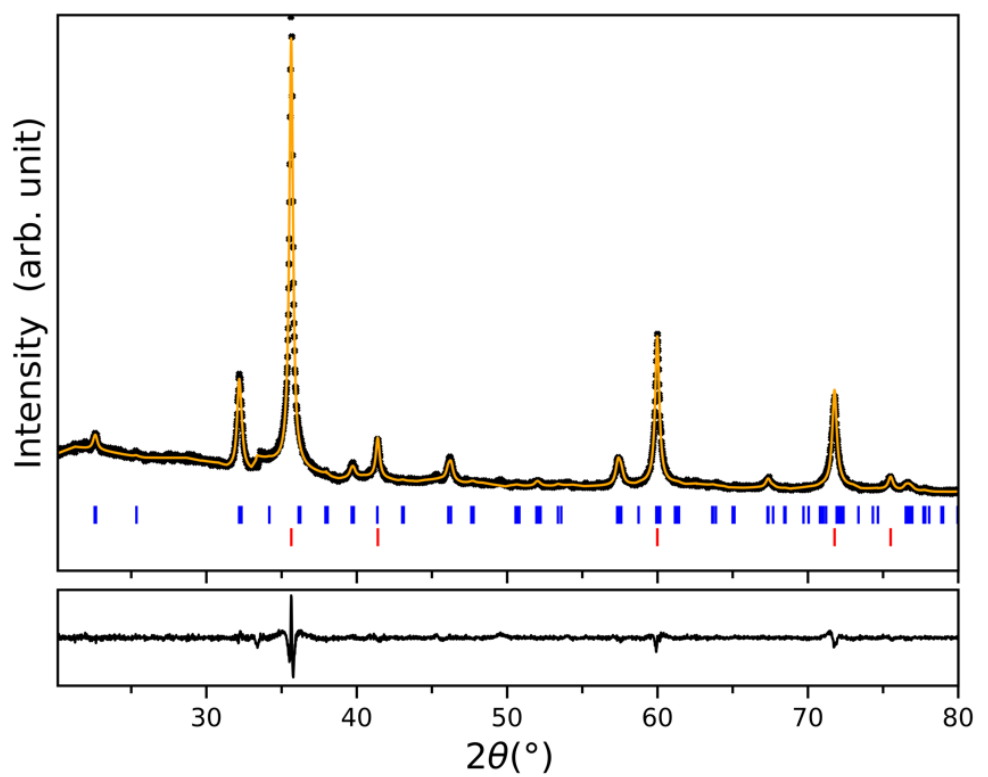

Figure S3. Observed (black), calculated (orange full line), and difference (black full line) XRD patterns of the SG-LFO/ $\beta$-SiC foam catalyst recorded on a Brucker D8 Discover diffractometer $(\lambda=1.54056 \AA)$, equipped with a LynxEye XE-T detector, a motorized anti-scatter screen and a Si low background sample holder for minimizing at the maximum the background noise. The positions of the Bragg reflections are represented by vertical bars, in blue for the reflexes indexed in the Pbnm orthorhombic unit cell of $\mathrm{LaFeO}_{3}$ and in red for those of the fcc $\beta$-SiC foam support. 


\section{Figure S4}

The theoretical variation of the peak intensities was computed for characterizing the detectability and the sensitivity to structural Ti of some selected characteristic Bragg peaks of the LFO phase. Both features were assessed by representing the normalized intensities $\left(\mathrm{I}_{\mathrm{hk}} / \mathrm{I}_{112}\right)$ and their relative variations as a function of the Ti amount inserted within the structure, respectively, as shown in Figures S4A and S4B.
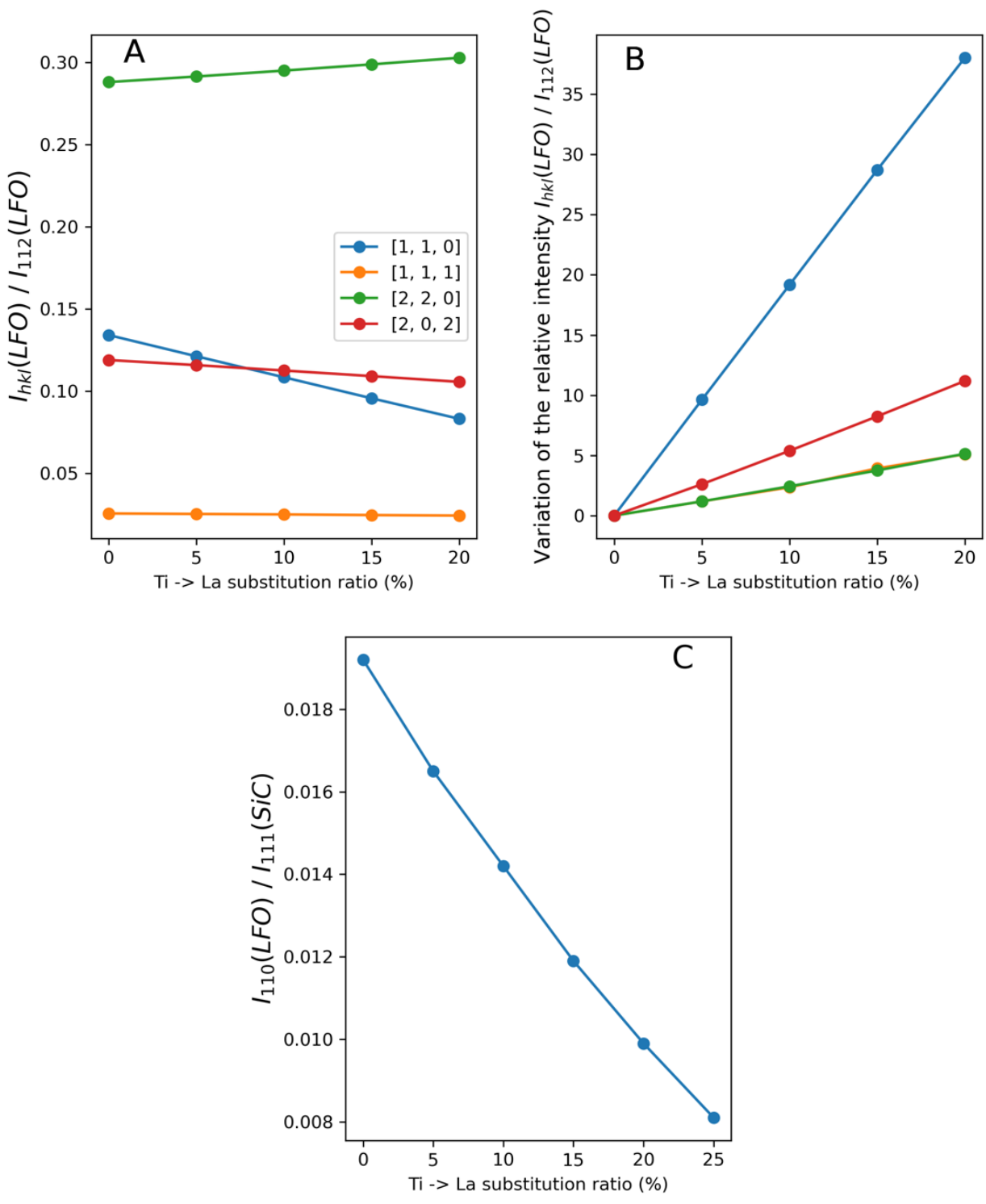
Figure S4. (A) Simulated normalized intensity $\mathrm{I}_{\mathrm{hkl}}(\mathrm{LFO}) / \mathrm{I}_{112}(\mathrm{LFO})$ and (B) its relative variation as a function of the $\mathrm{Ti} \rightarrow \mathrm{La}$ substitution ratio within the LFO structure for selected characteristic Bragg peaks, namely (110), (111), (220) and (202). They characterize the detectability and the sensitivity of the (hkl) peak to the insertion of $\mathrm{Ti}$ into the LFO structure, respectively. (C) Simulated normalized intensity $\mathrm{I}_{110}(\mathrm{LFO}) / \mathrm{I}_{111}(\mathrm{SiC})$ of the (110) peak of LFO for a sample consisting in a SiC matrix with $12 \%$ of LFO, the (111) peak being the most intense in the case of fcc $\beta$-SiC. 


\section{Figure S5}
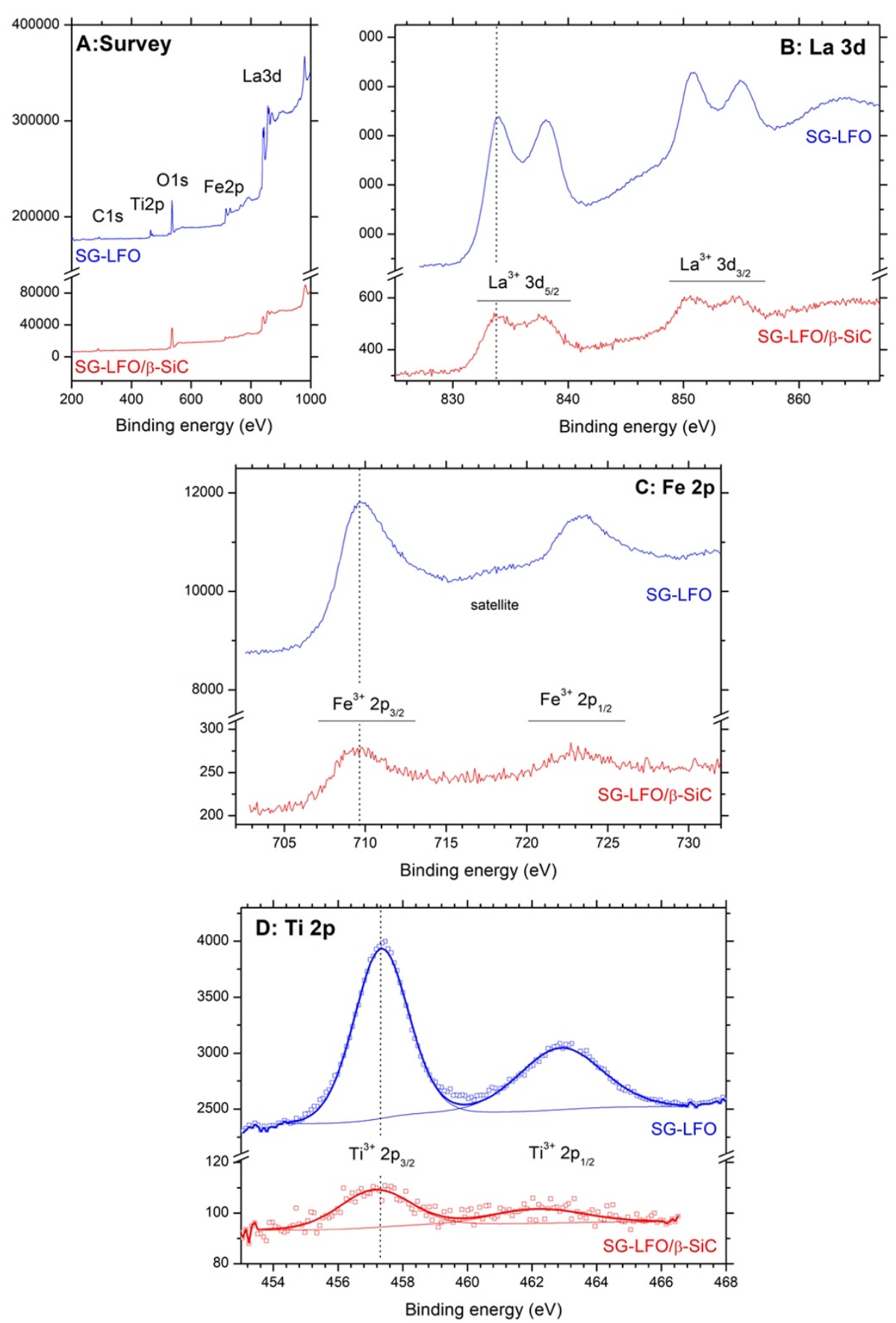

Figure S5. XPS profiles recorded on both the SG-LFO/ $\beta-\mathrm{SiC}$ foam and the SG-LFO catalysts, (A) wide scan survey spectrum, (B) La 3d, (C) Fe 2p and (D) Ti 2p orbitals.

X-ray photoelectron spectroscopy (XPS) characterization was performed on a ThermoVGMultilabESCA3000 spectrometer (Al $\mathrm{K} \alpha$ anode at $\mathrm{h} \lambda=1486.6 \mathrm{eV}$ ). The 
energy shift due to electrostatic charging was subtracted using the adventitious sp2 carbon C 1s band at $284.6 \mathrm{eV}$. Contributions with Doniach-Sunjic shape and a' S-shaped' Shirley type background were used. 


\section{Figure S6}

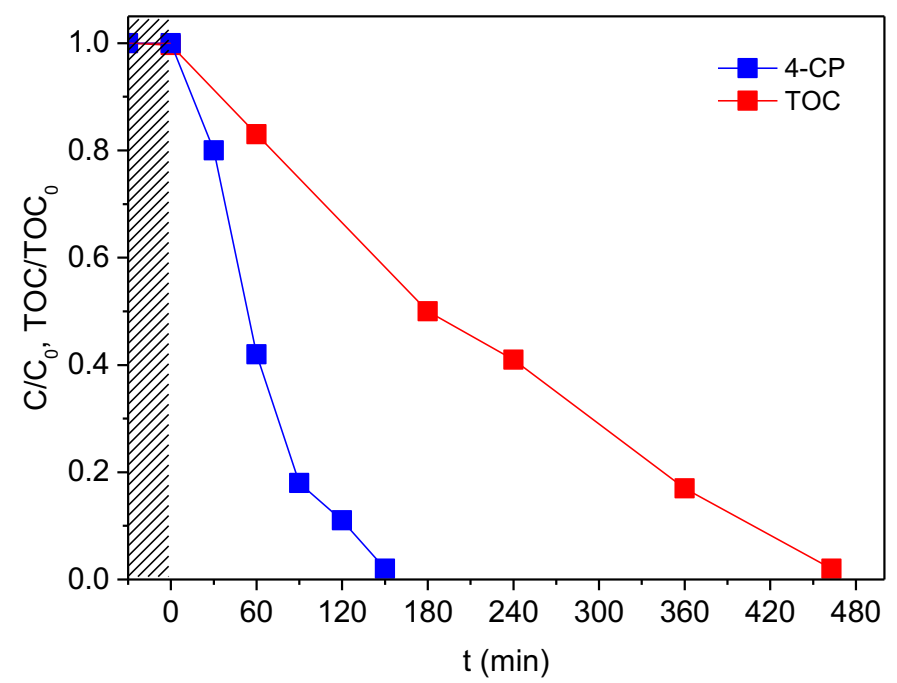

Figure S6. Time-evolution of both the $\mathrm{C} / \mathrm{C}_{0}$ and $\mathrm{TOC} / \mathrm{TOC}_{0}$ relative concentrations during the pure photocatalytic degradation of $4-\mathrm{CP}$ over the $\mathrm{P} 25 / \beta-\mathrm{SiC}$ foam. Conditions: $[4-\mathrm{CP}]_{0}=25 \mathrm{mg} / \mathrm{L} ; \mathrm{T}=25^{\circ} \mathrm{C} ; \mathrm{UV}-\mathrm{A}$ irradiance of $60 \mathrm{~W} \mathrm{~m}^{-2}$.

\section{Immobilization protocol.}

A reference $\beta$-SiC foam-supported $\mathrm{TiO}_{2}$ catalyst with $15 \mathrm{wt} \%$ of Aeroxide $C \mathrm{TiO}_{2} \mathrm{P} 25$ was prepared via the classical deposition method consisting in successive dippings of the foam into a $15 \mathrm{~g} \mathrm{~L}^{-1} \mathrm{TiO}_{2} \mathrm{P} 25$ ethanolic suspension, with intermediate rinsing steps with ethanol solution, followed by drying at $100^{\circ} \mathrm{C}$ and a final calcination treatment at $380^{\circ} \mathrm{C}$. Prior to deposition, the bare $\beta-\mathrm{SiC}$ foam was decarboned for $2 \mathrm{~h}$ at $700^{\circ} \mathrm{C}$ in air for removing the residual unreacted carbon species by combustion. The $\mathrm{TiO}_{2}$ content of 15 $\mathrm{wt} \%$ relative to the total foam weight was previously optimized [1] and determined by weighing the $\mathrm{TiO}_{2} / \beta-\mathrm{SiC}$ foam.

[1] Kouamé, A. N.; Masson, R.; Robert, D.; Keller, N.; Keller, V. $\beta$-SiC Foams as a Promising Structured Photocatalytic Support for Water and Air Detoxification. Catal. Today 2013, 209, 13-20. 
Figure S7
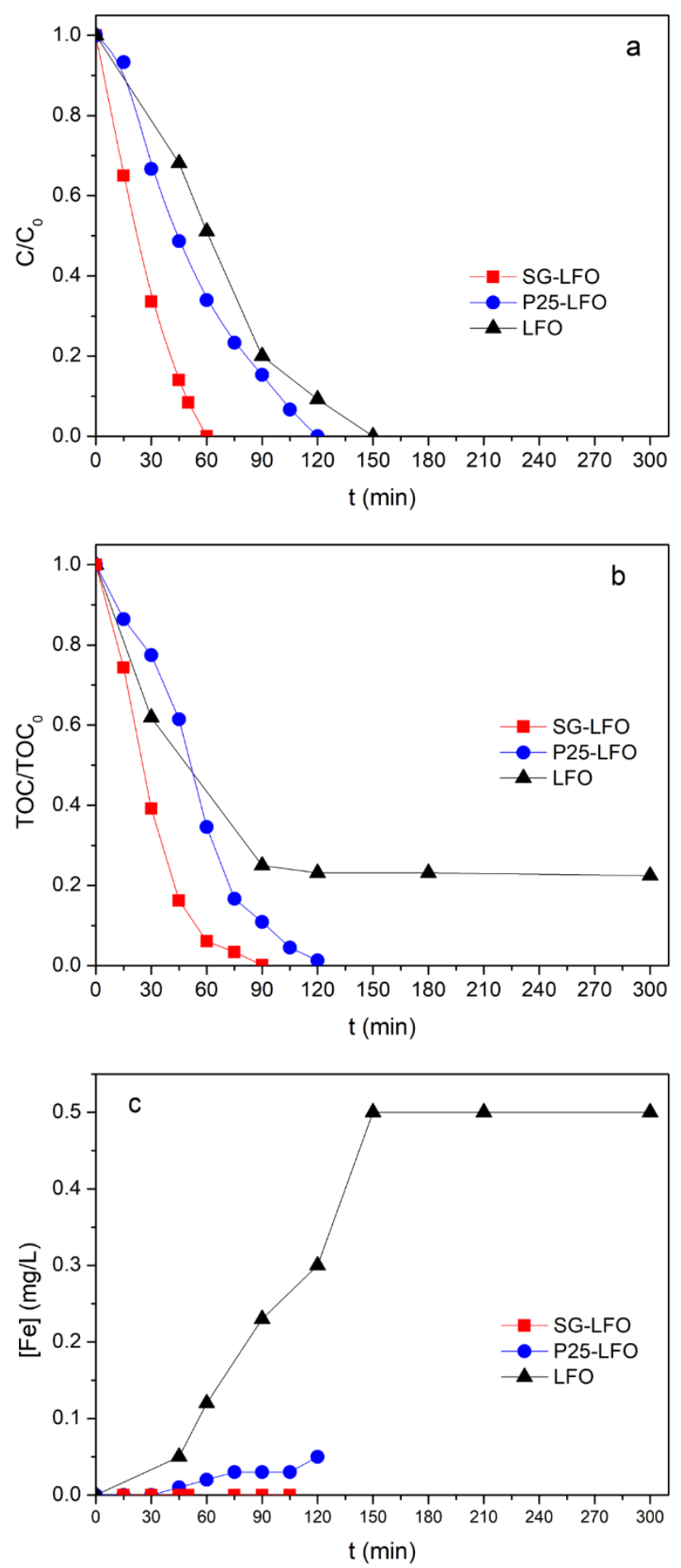

Figure S7. Evolution with time under irradiation of (a) the relative 4-CP concentration, (b) the relative TOC concentration and (c) the concentration of leached Fe in the solution during the combined photo-Fenton and photocatalytic degradation of 4-CP over the pristine LFO and both Ti-substituted P25-LFO and SG-LFO catalysts as powders. Conditions: $[4-\mathrm{CP}]_{0}=25 \mathrm{mg} / \mathrm{L} ;\left[\mathrm{H}_{2} \mathrm{O}_{2}\right]_{0}=125 \mathrm{mg} / \mathrm{L} ; \mathrm{T}=25^{\circ} \mathrm{C}$; $[$ cat $]=0.5 \mathrm{~g} / \mathrm{L} ; \mathrm{UV}-\mathrm{A}$ 
irradiance of $60 \mathrm{~W} \mathrm{~m}^{-2}$. Data taken from Garcia-Munoz et al. and graphs adapted with permission from RSC [1].

Table S2. Apparent kinetic rate constants of 4-CP oxidation and mineralization derived from the time-evolution of the 4-CP and TOC concentrations, and concentration of Fe leached at the end of the test. Data taken from Garcia-Munoz et al. and Table adapted with permission from RSC [1].

\begin{tabular}{llll}
\hline Catalyst & $\mathrm{k}(4-\mathrm{CP}), \mathrm{min}^{-1}$ & $\mathrm{r}_{0}(\mathrm{TOC}), \mathrm{mg} \mathrm{L}^{-1} \mathrm{~min}^{-1}$ & {$[\mathrm{Fe}]$ leached, $\mathrm{mg} \mathrm{L}^{-1}$} \\
\hline LFO & 0.020 & 0.12 & 0.5 \\
P25-LFO & 0.017 & 0.18 & 0.05 \\
SG-LFO & 0.033 & 0.28 & $<0.001$ \\
\hline
\end{tabular}

[1] García-Muñoz, P.; Fresno, F.; Lefevre, C.; Robert, D.; Keller, N. Synergy Effect Between Photocatalysis and Heterogeneous PhotoFenton Catalysis on Ti-Doped $\mathrm{LaFeO}_{3}$ Perovskite for High Efficiency Light-Assisted Water Treatment, Catal. Sci. Technol. 2020, 10, 1299-1310. 